\title{
INVESTIGACIÓN Y FEDERALISMO: LA REFORMA DE LA LEY FUNDAMENTAL DE BONN DE 2014, ¿QUÉ CAMBIA? ${ }^{1}$
}

\author{
MARÍA JESÚS GARCÍA MORALES \\ Profesora Titular de Derecho Constitucional \\ Universidad Autónoma de Barcelona
}

SUMARIO

I. Introducción II. El Sistema de Investigación en Alemania y la distribución de competencias III. Los Antecedentes de la reforma de 2014. IV. La reforma de 2014. V. Y tras la reforma, ¿qué?: reflexiones finales y cuestiones abiertas.

\section{INTRODUCCIÓN}

El 1 de enero de 2015 entraba en vigor la última (de momento) reforma de la Constitución alemana. Se trata de la 60. ${ }^{a}$ Ley de modificación de la Ley Fundamental de Bonn (LFB), aprobada el 23 de diciembre de 2014, y a través de la cual se ha introducido un nuevo campo de juego para la Federación y los Länder en el ámbito de la investigación.

Dado que se trata de una reforma constitucional, dicha modificación ha tenido un amplio eco en la vida política alemana, y, como no podía ser de otra manera, en la doctrina iuspublicista de aquel país. Por el contrario, y a pesar de que en España se sigue con minuciosa atención el constitucionalismo alemán, esa reforma no ha sido objeto todavía de tratamiento doctrinal en nuestro país.

La reforma constitucional de 2014 afecta a un solo precepto de la Ley Fundamental de Bonn. En concreto, se da una nueva redacción al artículo 91b de la

1 La autora quiere agradecer la autorización para visitar la extraordinaria Biblioteca del Bundestag, donde se han podido consultar las fuentes y la documentación necesarias para la realización de este trabajo, así como hacer constar su agradecimiento al personal de dicha Biblioteca. Asimismo, la autora quiere agradecer la conversación y la información facilitada por el Sr. Joachim Fiebig, Referatsleiter, Jefe de la Unidad sobre Cooperación Bund-Länder del Ministerio federal de Educación e Investigación. 
Constitución germana y, más específicamente, a su primer apartado. Sin embargo, esa reforma de pequeños cambios cuantitativos, no debe dejar pasar por alto los grandes y sustanciales cambios cualitativos que introduce la misma para el federalismo alemán en un sector concreto y estratégico: la investigación.

En Alemania, la Federación no dispone de competencias legislativas exclusivas en dicho ámbito. En principio, la investigación es competencia de los Länder. Sin embargo, éstos se hallan ante el dilema de no poder renunciar a cooperar con la Federación, que dispone de mayor capacidad financiera, para cumplir con sus tareas en este campo. Esa cooperación representa una pérdida de decisión para ellos, pero resulta un atractivo instrumento para la Federación, pues fortalece su posición en aquel sector a través de la misma.

La reforma de 2014 no plantea, pues, una cuestión nueva para el federalismo alemán, sino un tema clásico en la historia de este sistema que aparece y reaparece cada cierto tiempo también en otros sectores. La cuestión que ha vuelto a suscitar dicha reforma no es, si la Federación y los Länder pueden cooperar en materia de investigación, sino en qué casos y mediante qué instrumentos pueden hacerlo.

A esta pregunta, la Ley Fundamental de Bonn ha dado distintas respuestas a lo largo del tiempo - y a través de distintas reformas- en el artículo 91b LFB, donde se regula la llamada «tarea común» entre la Federación y los Länder en materia de educación e investigación. Introducido por primera vez a finales de los años sesenta del siglo pasado, este precepto fue modificado en la gran reforma federal de 2006 y ha sido el objeto de la modificación de 2014 que se aborda en este trabajo.

El adecuado encuadre de esta reforma requiere una primera aproximación al sistema de investigación alemán y a la distribución de competencias en este sector (II.), el examen de los antecedentes de la reforma de 2014 (III.), las causas, el contexto y la génesis de esta nueva modificación constitucional (IV.1), qué solución ha dado al problema planteado (IV.2), para, llegados a este punto, proceder a valorar el alcance de esta reforma (V.).

\section{EL SISTEMA DE INVESTIGACIÓN EN ALEMANIA Y LA DISTRIBUCIÓN DE COMPETENCIAS}

En el ámbito europeo, Alemania tiene un alto nivel en el campo de la investigación. Uno de los retos de futuro en dicho campo pasa por mantener e incrementar esa posición. Por ello, el rendimiento, la sostenibilidad y la competitividad de la investigación en el contexto internacional están en la agenda gubernamental (federal y de los Länder) y forman parte del debate político, mediático y jurídico en aquel país.

Para consolidar ese alto estándar, es preciso crear las condiciones para una investigación de alta calidad y, simultáneamente, procurar la mejor formación a quie- 
nes en el futuro deberán proseguirla. Por tanto, sólo con calidad desde el inicio del itinerario educativo se puede mantener a posteriori un alto nivel en investigación ${ }^{2}$.

No obstante, en ese itinerario, los centros de enseñanza superior (Hochschulen) constituyen la columna vertebral del sistema de investigación. El concepto de centros de enseñanza superior que utiliza la Ley Fundamental de Bonn no se circunscribe solo a las Universidades. Dentro del mismo, se engloban también las Universidades de las Fuerzas Armadas alemanas, así como las Escuelas de Bellas Artes, Música y Pedagogía, Escuelas Superiores Técnicas, o Academias de Ciencias, independientemente de su titularidad pública o privada ${ }^{3}$.

Junto a los centros de enseñanza superior, en el sistema alemán, tiene gran importancia la investigación que se lleva a cabo en instituciones extrauniversitarias o fuera de los centros de enseñanza superior. Entre ellas, se cuentan prestigiosas sociedades y organismos científicos donde destacan la Sociedad Max-Planck (MPG), que se dedica a la investigación básica, con diversos Institutos diseminados en todo el territorio federal; o la Fundación Alemana de la Investigación científica (DFG) que opera también en distintas ramas del conocimiento y, particularmente, mediante la financiación de proyectos de investigación.

Otras grandes instituciones extrauniversitarias remarcables, también con centros de investigación en distintos puntos de Alemania, son: la Comunidad Helmholtz (HGF), que actúa sobre la investigación operativa y la puesta a disposición de infraestructuras científicas; la Sociedad Fraunhofer (FhG), orientada especialmente a la investigación aplicada y a la transferencia de la investigación; o la Comunidad Leibniz (WGL), que a través de sus Institutos investiga sobre materias tan diversas como Ciencias Naturales, Ingenierías, Ciencias Medioambientales o Ciencias Sociales y Humanidades ${ }^{4}$.

La Ley Fundamental de Bonn hace referencia a la investigación en tres preceptos. Por una parte, en sede de derechos fundamentales, la Constitución alemana prevé que: «la ciencia, la investigación y la enseñanza científica son libres» (art. 5.3 LFB). Por otro lado, la investigación aparece en el sistema de reparto competencial, en concreto entre las competencias legislativas de la Federación, donde ésta dispone de una competencia concurrente en materia de «fomento de la investigación científica» (art. 74.1.13 LFB); así como en sede de las llamadas

2 M. SeckelmanN, «Bildung und Wissenschaft im Bundesstaat. Entwurf eines Gesetzes zur Förderung der föderalen Kooperation im Wissenschaftsbereich», Zeitschrift für Rechtspolitik, n. ${ }^{\circ}$ 82, 2013, p. 83.

3 O. JAUCH, Wissenschaftsförderung nach der Reform des Wissenschaftsföderalismus: Kompetenzen und Zusammenwirken von Bund und Ländern im Bereich Wissenschaft und Forschung in der Bundesrepublik Deutschland unter besonderer Berïcksichtigung der Gemeinschaftsaufgaben, Tesis, Hamburg, 2013, p. 21. Asimismo, entre la abundante doctrina, H.G. Henneke, «Artikel 91b» en B. Schmidt-Bleibtreu, H. Hofmann, H.-G. HenneKE (Hrsg.), GG Kommentar zum Grundgesetz, 13.Aufl., Carl Heymanns Verlag, Köln, 2014, p. 2145.

4 J. E. ZöllnER, «Wissenschaft und Forschung als Gemeinschaftsaufgabe von Bund und Länder Herausforderung und Aufgabenteilung in einen föderalen System», en E. Thies, N. LeIBINGER-KammüLLER (Hrsg.), Politik für Wissenschaft und Forschung in Deutschland, im Auftrag der Konrad-Adenauer-Stiftung Düsseldorf, Droste, Düsseldorf, 2014, pp. 57-58. 
tareas comunes entre la Federación y los Länder, donde ambas instancias pueden cooperar en el fomento de «la ciencia, la investigación y la enseñanza científica» (art. 91b LFB).

Hecha esta precisión terminológica, procede examinar con más detalle cuál es el marco competencial en materia de investigación ${ }^{5}$. No en vano, dos de las ocasiones en las que la Ley Fundamental de Bonn menciona la investigación son en sede competencial y de reparto vertical del poder.

Por lo que respecta a las competencias legislativas, en Alemania, los Länder son las instancias competentes, salvo en aquellos casos en los que la Constitución disponga otra cosa (art. 30 LFB). Los Länder son, en principio, también los que ejecutan las leyes federales (art. 83 LFB) y los que asumen también los gastos de ejecución (el llamado principio de conexidad o Konnexitätsprinzip: art. 104a 1 LFB). Los Länder son las instancias sobre las que recaen principalmente las competencias en materia de investigación ${ }^{6}$. La Federación nunca ha dispuesto de competencias legislativas exclusivas, ni en materia de educación — donde se incluye la enseñanza superior-, ni específicamente en materia de investigación. No las previó la Ley Fundamental de Bonn en 1949 y no se han introducido mediante ninguna de las muchas reformas ulteriores del federalismo alemán.

En la versión vigente de Constitución alemana, la Federación ostenta competencias concurrentes en dicho ámbito: en concreto, la competencia para el fomento de la investigación científica (die Förderung der wissenschaftlichen Forschung) (art. 74.1.13 LFB), la competencia sobre admisión en la Universidad y diplomas universitarios (art. 74.1. 33 LFB) y, en cuanto al profesorado funcionarial, la competencia sobre derechos y obligaciones de los funcionarios (art. 74.1.27 LFB). La reforma federal de 2006 suprimió la competencia federal más importante de que disponía la Federación en este campo: la legislación marco sobre los principios generales en materia de enseñanza superior (anterior art. 75.1.1a LFB), que se había introducido con la 22. ${ }^{a}$ reforma de la Ley Fundamental de Bonn, en 1969 , en pleno auge del federalismo cooperativo.

De esta manera, en la actualidad, la Federación únicamente dispone de competencias concurrentes en investigación. Ello significa que el Bund puede aprobar leyes en determinados ámbitos si concurren una serie de presupuestos. Tras la reforma federal de 2006, los Länder pueden legislar en estos casos «mientras y en la medida que la Federación no haya hecho uso mediante ley de su competencia legislativa» (art. 72.1 LFB). Sin embargo, hay una serie de materias en las que la Federación está sometida a la cláusula de imprescindibilidad (Erforderlichkeitsklausel), esto es, tiene la competencia legislativa «si y en la medida que sea necesaria una regulación legislativa general en interés de la totalidad del Estado para

5 Al respecto, ampliamente en A. DitTmann, Bildung und Wissenschaft in der bundesstaatlichen Kompetenzordnung, Stifterverband für die Deutsche Wissenschaft, Essen, 2004, pp. 21-51.

6 A. Kienemund, «Art. 91b» en D. Hömig, H.A. Wolff (Hrsg.), Grundgesetz für die Bundesrepublik Deutschland, 11. Aufl, Nomos, Baden Baden, 2016, p. 664. 
la creación de condiciones de vida equivalentes en el territorio federal o el mantenimiento de la unidad jurídica o económica» (art. 72.2 LFB) ${ }^{7}$.

En materia de investigación, la competencia concurrente más importante de que dispone la Federación es el fomento de la investigación científica del artículo 74.1 13 LFB. Se trata de una de las competencias sometida a la cláusula de imprescindibilidad. Dicho precepto dispone que la Federación ostenta la legislación concurrente en «la regulación de las ayudas para la formación y el fomento de la investigación científica».

Las ayudas para la formación se introdujeron en la Constitución alemana también en la 22. ${ }^{a}$ reforma de la misma en 1969. Se trata de ayudas a personas individuales que se encuentran en su fase de formación sean estudiantes universitarios o no, pero no ya graduados. En desarrollo de esta competencia, la Federación ha aprobado desde 1971 hasta el presente sucesivas versiones de la Ley federal para el fomento de ayudas a la formación (Bundesausbildungsförderungsgesetz-BAf̈̈ $G)^{8}$.

La competencia federal concurrente sobre «el fomento de la investigación» está en la Ley Fundamental de Bonn desde 1949. El concepto de «investigación» (Forschung) que utiliza la Constitución alemana ha sido precisado por el Tribunal Constitucional Federal como «la actividad intelectual orientada a generar nuevos conocimientos de una forma metódica, sistemática y verificable» ${ }^{9}$. Por su parte, en «fomento» (Förderung) se engloban medidas de apoyo a la investigación, dentro las cuales pueden subsumirse medidas organizativas, de planificación y, sobre todo, la asignación de medios financieros ${ }^{10}$. Se incluye el fomento tanto de la investigación universitaria, como la desarrollada fuera de los centros de enseñanza

7 Los presupuestos que deben concurrir en el caso de las competencias concurrentes han ido modificándose a través de diversas reformas constitucionales que han tendido a dar más espacio a los Länder y a evitar un abuso de este tipo de legislación por parte de la Federación. En la redacción original, los Länder podían aprobar leyes en la medida en que la Federación no hubiera aprobado una ley federal, cosa que podría hacer siempre y cuando fuera necesario si concurrían una serie de circunstancias (la llamada cláusula de necesidad, Bedïrnisklausel), tales como la necesidad de una uniformidad de las condiciones de vida. Posteriormente, para evitar el uso expansivo que hacía la Federación de dicha cláusula, la reforma de 1994 intentó acotar más los presupuestos de la intervención legislativa federal siempre que fuera imprescindible [de la llamada cláusula de necesidad se pasó a la cláusula de imprescindibilidad (Erforderlichkeitsklausel)]. El fomento de la investigación científica no es uno de los ámbitos donde quepa la llamada legislación divergente (art. 72.3 LFB), esto es, la posibilidad desde 2006 de que los Länder aprueben, una vez adoptada la ley federal en las competencias concurrentes, leyes diferentes. Las leyes leyes divergentes de la norma federal sí caben en materia de admisión en las Universidades y diplomas universitarios. Sobre el tema, más ampliamente, A. Guckelberger, «Bildung und Föderalismus», en I. Härtel (Hrsg.), Handbuch Föderalismus, Band III, Springer, Berlin, Heidelberg, 2012, pp. 232-233. Sobre la legislación concurrente en la reforma federal de 2006, A. ARRoyo GiL, La reforma constitucional del federalismo alemán, Institut d'Estudis Autonòmics, Barcelona, 2009, pp. 48-70.

8 H. D. Jarass, B. Pieroth, «Art. 74», Grundgesetz für die Bundesrepublik Deutschland. Kommentar, 14. Aufl., 2016, C.H. Beck, München, p. 895.

9 BVerfGE 35, 79 (113) (Hochschul-Urteil).

10 H. D. Jarass, B. Pieroth, «Art. 74», Grundgesetz für die Bundesrepublik Deutschland. Kommentar, op. cit., pp. 895-896; H.G. HenNeKe, «Artikel 91b», op. cit., p. 2144. 
superior. No se incluye el fomento de proyectos dedicados a la docencia. En un sistema donde se ha criticado el uso expansivo que ha hecho la Federación de los presupuestos para utilizar sus competencias concurrentes, debe destacarse que la Federación nunca ha utilizado la competencia concurrente en materia de fomento de la investigación ${ }^{11}$.

Además de dicha competencia, el marco competencial en materia de investigación en la Ley Fundamental de Bonn cuenta también con una serie de previsiones constitucionales que fueron introducidas por primera vez en 1969 y que - con diversas redacciones hasta la versión vigente-, habilitan la cooperación financiera entre la Federación y los Länder en este campo.

Para entender el alcance de esa cooperación, debe partirse de que la investigación en Alemania se considera un bien colectivo ${ }^{12}$. Por ello, el fomento de la investigación se concibe como una tarea del Estado que deriva del principio de Estado social y como una obligación para el mismo. Al ser un bien colectivo, la investigación —al igual que la educación — no puede tener sólo una financiación privada, sino que debe contar con recursos públicos. El gran problema de la investigación - y de una investigación de calidad - es su creciente necesidad de financiación. Por ello, en un sistema territorialmente descentralizado, como el alemán, esa financiación pública precisa la suma de recursos entre el poder central y las instancias territoriales. En definitiva, y como indica la Profesora Margrit SECKLEMANN: «la producción de bienes colectivos requiere en el Estado federal alemán la cooperación entre la Federación y los Länder « ${ }^{13}$.

Entre las vías que la Constitución alemana prevé para articular la cooperación financiera, destacan particularmente las llamadas tareas comunes. La disposición más importante que regula la investigación en la Ley Fundamental de Bonn y, en especial, la cooperación financiera entre la Federación y los Länder es la llamada tarea común prevista en el artículo 91b LFB relativa al fomento de la investigación. Su examen y evolución en el fomento de la investigación, así como otras previsiones concatenadas en materia de cooperación financiera, se abordan con detalle en los epígrafes siguiente.

El marco competencial en materia de investigación no se agota en las previsiones que contempla el texto de la Ley Fundamental de Bonn. La distribución de compentencias en materia de investigación no puede cerrarse sin hacer referencia a las llamadas competencias no escritas en función de las cuales la Federación puede intervenir en determinados supuestos, aun no teniendo competencia expresamente prevista, $y$, en ocasiones, respaldada por una praxis consentida muy dilatada en el tiempo como en este caso. En ese sentido, la Federación y los Länder suscribieron un Acuerdo en 1971 (el llamado Flurbereiningungsabkommen)

11 O. JAUCH, Wissenschaftsförderung nach der Reform des Wissenschaftsföderalismus, op. cit., p. 66.

12 Ibidem, pp. 22-23.

13 M. SeckelmanN, «Bildung und Wissenschaft im Bundesstaat. Entwurf eines Gesetzes zur Förderung der föderalen Kooperation im Wissenschaftsbereich», op. cit., p. 84. 
donde pactaron un catálolo de tareas que la Federación podía financiar, aunque no tuviera una competencia expresa, y que, en materia de investigación se concretan en la financiación federal de Institutos alemanes en el extranjero u otras actividades de relevancia internacional en este ámbito, o los proyectos de investigación de gran envergadura (Großforschung) de especial interés científico para el conjunto del Estado y que requieren una financiación extraordinaria, tales como la investigación nuclear, oceonagrafía o aeroespacial ${ }^{14}$.

\section{LOS ANTECEDENTES DE LA REFORMA DE 2014}

En ese marco competencial, el principal fundamento normativo de la cooperación entre la Federación y los Länder en investigación es la tarea común del artículo 91b LFB. Las tareas comunes son una peculiaridad del federalismo alemán que no tiene parangón en otras Constituciones federales del entorno europeo $^{15}$. Tras la regulación de las competencias legislativas de la Federación (Poder Legislativo VII. arts. 70 LFB ss.), la ejecución de las leyes federales y la administración federal (Ejecutivo, VIII. arts. 83 ss.), la Ley Fundamental de Bonn prevé desde 1969 las tareas comunes y la cooperación administrativa (VIIa. arts. 91a ss. LFB), esto es, sectores en los que la Federación y los Länder codeciden y financian de forma conjunta. El nuevo artículo 91b LFB que entró en vigor el 1 de enero de 2015 - y que es objeto de este trabajo — debe su introducción a la revisión de 1969 y resultó sustancialmente modificado en la reforma federal de 2006.

\section{La reforma de 1969}

La reforma constitucional de 1969 ha sido la modificación más importante de la Ley Fundamental de Bonn desde 1949, hasta la gran reforma federal de 2006 y 2009. Dicha reforma, conocida como la reforma de la Constitución financiera, se llevó a cabo bajo la primera gran coalición entre los dos principales partidos alema-

14 Sobre las compentencias no escritas en el sistema alemán. E. Albertí Rovira, Federalismo y cooperación en la República Federal Alemana, CEC, Madrid, 1986, pp. 83-84. Específicamente, sobre estas competencias en materia de investigación, R.W. MAIER, «Bildung und Forschung im kooperativen Föderalismus. Zu den Finanzierungskompetenzen des Bundes», Die Öffentliche Verwaltung,n. ${ }^{\circ}$ 56, 2003, pp.800-802. Asimismo, J. Wieland, D. Dohmen, Bildungsföderalismus und Bundesfinanzierung, Friedrich Ebert Stiftung, Berlin, 2011, pp. 31-34. En particular, sobre el llamado Flurbereinigungsabkommen, que propiamente es un borrador, a cuyo contenido la praxis le da el valor de lo pactado, vid. R. Goroncy, «Die Bundeskompetenzen für die Forschungsförderung nach dem Entwurf des sogennanten Flurbereiningungsabkommen», en Wissenschaftrecht, Wissenschaftsverwaltung, Wissenschaftsförderung: Zeitschrift für Recht und Verwaltung der wissenschaftliche Hochschulen und der wissenschaftsplegenden und -fördernden Organisationen und Stiftungen, Band 5, 1972, pp. 135-160.

15 Sobre el origen de las tareas comunes en el Derecho previo a la Ley Fundamental de Bonn, H. FABer, I. Richter, «Art. 91a/91b», Kommentar zum Grundgesetz für die Bundesrepublik Deutschland, Band 2, Luchterhand, Neuwied, 1984, p. 934. 
nes: la democracia cristiana (CDU/CSU) y la socialdemocracia (SPD). La 21. ${ }^{a}$ Ley de modificación de la Ley Fundamental de Bonn, de 12 de mayo de 1969, cuya entrada en vigor se produjo el 1 de enero de 1970, introducía una modificación cualitativa en el federalismo alemán. Frente a la originaria separación de ámbitos entre la Federación y los Länder, esta reforma representaba el reconocimiento constitucional del federalismo cooperativo frente al federalismo dual del diseño inicial y, con ello, la institucionalización de la interacción entre la Federación y los Länder ${ }^{16}$.

Los motivos que impulsaron el fortalecimiento de la cooperación en 1969 fueron económicos, sociales y técnicos. En 1966, Alemania se enfrentaba a su primera gran crisis tras el milagro económico alemán, lo cual requería unidad de acción entre todos los niveles de gobierno de la República Federal. Más allá de causas económicas, el desarrollo social y la propia dimensión suprarregional de los problemas exigía una acción coordinada y conjunta entre la Federación y los Länder, que ya se estaba produciendo en la praxis, en muchos ámbitos y particularmente en el campo de la investigación.

Esa situación generaba, como describió perfectamente el Profesor Dieter GRIMM, una «transformación clandestina del sistema original» ${ }^{17}$, porque la cooperación tan habitual en la historia de federalismo alemán había sido una cooperación sobre todo entre Länder, pero ahora el novum y también el riesgo para el sistema era la entrada de la Federación en instrumentos cooperativos con los Länder que les aseguraba fondos financieros en ámbitos de aquellos y, con ello, también la consiguiente erosión de su libertad de acción a cambio de ese dinero.

Con ello, la reforma de 1969 representó dar basamento constitucional a una serie de prácticas cooperativas previas que se situaban en los límites o contra el tenor literal de la Constitución alemana antes de la reforma. La revisión de 1969 fue también - y primordialmente- una forma de financiar tareas estatales. Sin embargo, también significó la aceptación de una nueva distribución vertical y horizontal del poder. En efecto, la Ley Fundamental reconocía originariamente la legislación federal, la ejecución de leyes federales, y el federalismo judicial, pero ahora surgía un nuevo ámbito, la planificación, y con ello, la decisión y la financiación conjunta entre la Federación y los Länder ${ }^{18}$.

La reforma de 1969 consagró la política de entrelazamiento entre ambas instancias en el proceso de adopción de decisiones (la conocida como Politikverflechtung ${ }^{19}$ ). A finales de los años sesenta, se pensó que esta forma de hacer política basada en el

16 En ese sentido, el trabajo clásico de K. Hesse, Der unitarische Bundesstaat, C.F. Müller, Karlsruhe, 1962.

17 D. Grimm, «Les relations financières dans le système federal allemand», en D. Grimm et al., Les problèmes financiers dans l'État régionalisé, Bruylant, Bruxelles, 1981, p. 3.

18 Sobre la reforma de 1969, vid. H. Kilper, R. LhotTA, Föderalismus in der Bundesrepublik Deutschland, Leske Budrich, Opladen, 1996, pp. 183-207, así como el extenso trabajo de E. Albertí Rovira, Federalismo y cooperación en la República Federal Alemana, CEC, Madrid, 1986, pp. 485-565.

19 La expresión Politikverflechtung tiene su origen en la bibliografia de la Ciencia política alemana y, en particular, ha gozado de predicamento a partir de la obra de F.W. SCHARPF, B. ReISSERT, F. SCHNABEL, Politikverflechtung: Theorie und Empirie des kooperativen Föderalismus in der Bundesrepublik, Kronberg/Ts., 1976. 
acuerdo incrementaba el grado de aceptación y la eficiencia de la acción pública ${ }^{20}$. Además, la gran coalición de 1966 representó también una nueva política que necesitaba instrumentos planificadores y, con ello, el acuerdo y la cooperación entre la Federación y los Länder, en sectores estructurales para lograr el equilibrio económico y social en todo el territorio federal ${ }^{21}$.

El buque insignia de ese nuevo federalismo fue la introducción en la Constitución alemana de la forma más intensa de interacción entre ambas instancias, en ámbitos inicialmente exclusivos de los Länder, a través del instituto de las llamadas tareas comunes (Gemeinschaftsaufgaben) entre la Federación y los Länder: las tareas comunes obligatorias (art. 91a LFB) y las tareas comunes facultativas (art. 91b LFB) ${ }^{22}$.

Entre las tareas comunes obligatorias del artículo 91a LFB, se contaban una serie de ámbitos donde la Federación y los Länder preceptivamente debían actuar de forma conjunta: entre ellos, la enseñanza superior, el equilibrio regional, la mejora de la estructura agraria o de la protección de costas.

Por lo que respecta a la enseñanza superior (pieza clave de la investigación), uno de los ámbitos donde ambas partes debían actuar de forma mancomunada era la ampliación y la nueva construcción de centros de enseñanza superior, incluidos los hospitales clínicos universitarios. Dicha interacción precisaba de un presupuesto: la Federación podía intervenir en el cumplimiento de tareas de los Länder siempre y cuando dichas «tareas sean significativas para la colectividad y la intervención de la Federación sea necesaria para mejorar las condiciones de vida» (art. 91a. 1 LFB). La propia Constitución preveía que el instrumento a través del cual se especificarían dichas tareas comunes sería una ley federal que debía contar con el consentimiento del Bundesrat ${ }^{23}$.

Sin embargo, en el ámbito de la investigación, el precepto más importante que introducía la reforma de 1969 era el artículo 91b LFB $^{24}$. A diferencia de las tareas comunes obligatorias, aquí no se preveía una obligación de cooperación,

20 R. STURM, «Zusammenarbeit im deutschen Föderalismus», Informattionen zur politischen Bildung, $1-2 / 2013$, pp. 14-16.

21 H. FABer, I. Richter, «Art. 91a/ 91b», Kommentar zum Grundgesetz für die Bundesrepublik Deutschland, op. cit., p. 966.

22 Dos trabajos clásicos sobre las tareas comunes, J.A. FroweIn e I. v. MüNCH, «Gemeinschaftsaufgaben im Bundesstaat», en Veröffentlichungen der Vereinigung der Deutschen Staatsrechtslehrer, Heft 31, 1973, pp. 13-47, y 53-83. Sobre las tareas comunes en el federalismo cooperativo, S. KRopP, Kooperativer Föderalismus und Politikverflechtung, VS Verlag, Wiesbaden, 2010, pp. 81-85.

23 Asimismo, se previó que la Federación asumía la mitad de los gastos en cada Land en los dos primeros ámbitos y, al menos la mitad, en el caso de la mejora de la estructura agrícola y la protección de costas. Poco después de la entrada en vigor de la reforma, se aprobó la Ley federal sobre la tarea común de ampliación y nueva construcción de centros de enseñanza superior, de 1 de septiembre de 1969, donde se regulaban unas Comisiones planificadoras formadas por representantes de la Federación y de los Länder que adoptaban resoluciones con el voto favorable del Bund y de la mayoría de los Lander, sin vincular a quienes hubieran votado en contra.

24 A. Dittmann, Bildung und Wissenschaft in der bundesstaatlichen Kompetenzordnung, op. cit., pp. 83-93. 
sino la posibilidad de interacción entre la Federación y los Länder en los siguientes términos:

«(1) La Federación y los Länder pueden en virtud de convenios cooperar en la planificación de la enseñanza y en el fomento de instituciones y proyectos de investigación científica de alcance suprarregional. (2) La distribución de costes se regula mediante convenio».

En el statu quo previo a la reforma, en el campo de la educación, la competencia residía en los Länder, que se autocoordinaban en este ámbito a través de la Conferencia de Cultura de los Länder creada en 1948, antes de la aprobación de la propia Ley Fundamental de Bonn. Históricamente, educación ha sido - y sigue siendo- en el federalismo alemán una cuestión de los Länder y un signo de su soberanía cultural (Kulturbobeit), así como de su identidad estatal, muy sensible frente a posibles injerencias federales y europeas. La situación era distinta en el campo de la investigación donde los Länder entre sí y con la Federación habían ido constituyendo órganos comunes, o suscribiendo convenios entre ellos ${ }^{25}$.

La cuestión de la financiación de la investigación se planteó tempranamente: dos meses después de la aprobación de la Ley Fundamental de Bonn, los Länder occidentales se reunieron para encarar el tema, suscribieron el llamado Acuerdo de Königsteiner (Königsteiner Abkommnen), de 30/31 de marzo de 1949, para la financiación de organizaciones científicas, y adoptaron la fórmula de cálculo basada en la aportación de cada Land: la llamada fórmula de Königsteiner (Königsteiner Schliissel), que todavía hoy se utiliza y que se calcula teniendo en cuenta la presión fiscal de cada Land (en dos terceras partes) y su número de población (en una tercera parte). Desde 1957, la Federación participa en dicho convenio y financia con los Länder por mitad múltiples organismos científicos (entre ellos, la Fundación Alemana de Investigación Científica o las Sociedades Max-Planck, o Fraunhofer $)^{26}$.

Esa praxis basada en el acuerdo entre la Federación y los Länder fue la razón por la que el fomento de la investigación —y también finalmente la planificación de la enseñanza - se trataron como una tarea común facultativa (no dentro de las obligatorias). Por tanto, en este ámbito, se optó por la flexibilidad que permite el acuerdo entre la Federación y los Länder, así como la formalización de sus compromisos a través de un instrumento pactista — y largamente consolidado en el federalismo alemán- como son los convenios ${ }^{27}$.

25 A. Guckelberger, «Bildung und Föderalismus», op. cit., pp. 223-224; T. Köstlin, Die Kulturboheit des Bundes, Duncker \& Humblot, Berlin, 1989, pp. 77-83.

26 M. Abelein, Die Kulturpolitik des Deutschen Reiches und der Bundesrepublik Deutschland, Springer Fachmedien, Wiesbaden, 1968, p. 226.

27 En este sentido, el Dictamen de la llamada Comisión Troeger, presentado en 1966, cuyos trabajos fueron la base de la reforma de 1969, Kommission für die Finanzreform, Gutachten über die Finanzreform in der Bundesrepublik, Kohlhammer, Deutscher Gemeindeverlag, Stuttgart, Köln, Berlin, Mainz, 1966, pp. 38-39. 
El acuerdo de desarrollo de la tarea común se concretó con la creación de la Comisión del Bund y los Länder para la planificación de la educación y el fomento de la investigación (Bund-Länder-Kommission für Bildungsplanung und Forchungsförderung-BLK). Inicialmente creada en 1970 para la planificación de la educación, esta Comisión extendió sus funciones también al fomento de la investigación científica a través de un Convenio marco posterior suscrito en 1975. Hasta su supresión el 31 de diciembre de 2007, dicha Comisión funcionó con un carácter bifronte: por un lado, en materia de planificación de la enseñanza y, por otro, en materia de fomento de la investigación. En este último caso, las funciones de la Comisión fueron principalmente buscar la coordinación en materia de investigación entre la Federación y los Länder y proponer a los Jefes de Gobierno de ambas instancias las necesidades de financiación de las grandes instituciones dedicadas a la investigación en Alemania, que son objeto de fomento (entre ellas, las ya mencionadas Fundación Alemana de Investigación Científica o las Sociedades Max-Planck, o Fraunhofer ${ }^{28}$.

Más allá de las tareas comunes de los artículos 91a y 91b LFB, también conocidas como las tareas comunes propias o auténticas (echte Gemeinschaftsaufgaben), la reforma constitucional de 1969, introdujo las llamadas falsas tareas comunes o tareas comunes impropias (unechte Gemeinschaftsaufgaben) donde se ubican las ayudas financieras de la Federación a los Länder (o Finanzhilfen del art. 104a.4 LFB en la versión de 1969), que han constituido también otro de los emblemas de la política de entrecruzamiento entre ambas instancias.

En cuanto instrumento adicional de financiación federal, las ayudas financieras han completado el marco normativo y financiero en materia de investigación desde 1969 hasta la actualidad. La introducción de estas ayudas en la Constitución alemana representó una importante excepción al principio de conexidad que contempla la Ley Fundamental de Bonn, según el cual, como se vio, cada uno de ellos asume por separado los gastos derivados del cumplimiento de sus tareas, de tal manera que quien tiene la competencia, asume su financiación, salvo que el texto constitucional disponga otra cosa (art. 104.1 LFG).

A través de las ayudas financieras, la Federación podía transferir dinero para inversiones especialmente relevantes de los Länder y de los municipios (asociaciones de municipios) en una serie de supuestos: la defensa contra una perturbación del equilibrio global de la economía, para compensar el diferente poder económico en el territorio federal, o bien para fomentar el crecimiento económico. Las

Asimismo, sobre cómo el artículo 91b 3. LFB recoge la praxis del Acuerdo de Königsteiner al referirse a los convenios, vid. M.-E. Geis, D. KRausnick, «Das Hochschulrecht im föderalen System der Bundesrepublik», I. Härtel (Hrsg.), Handbuch Föderalismus, Band III, Springer, Berlin, Heidelberg, 2012, p. 288.

28 Sobre la extinta Comisión Bund-Länder para la planificación de la educación y el fomento de la investigación, vid. H.P. FüsseL, «Kooperativer Föderalismus im Bildungswesen», Recht der Jugend und des Bildungswesens, 1989, p. 434, BLK-Informationen 2004, pp. 9-10 http://www.blk-bonn.de/papers/blk-Info-2004.pdf (consulta: 20/06/2016). 
ayudas financieras no son un mecanismo previsto específicamente para el fomento de la investigación (a diferencia del artículo 91b LFB), pero sí son un instrumento de cooperación financiera que la Federación puede utilizar en este ámbito al amparo de los supuestos vistos ${ }^{29}$.

\section{La reforma federal de 2006}

La reforma de 1969 es fundamental para entender por qué y para qué se introducen las tareas comunes en la Constitución alemana, pero también para comprender su significado en la propia sistemática de la Ley Fundamental de Bonn. Sin embargo, desde su introducción a finales de los años sesenta, las tareas comunes no han sido nunca un instrumento aceptado con complacencia, sino con mucha polémica, pues se han valorado como algo ajeno al sistema de separación de competencias entre la Federación y los Länder y como una vía de centralización que favorece la intervención federal en ámbitos de aquellos ${ }^{30}$.

Casi cuatro décadas después, el 28 de agosto de 2006, se aprobaba la primera etapa de la reforma federal de más envergadura que hasta ahora ha tenido la Constitución alemana (Föderalismusreform I). De nuevo, una reforma de tal calado se llevaba a cabo precedida por un dilatado debate y bajo un Gobierno de gran coalición entre las fuerzas democratacristianas y la socialdemocracia alemana (CDU/CDU y SPD). Se trataba de la segunda gran coalición que se producía tras la habida en el periodo 1966-1969 y bajo la cual se aprobó la reforma de la Constitución financiera antes comentada ${ }^{31}$

Si en 1969 la «palabra mágica» que inspiró y justificó la reforma era el «federalismo cooperativo», en 2006, uno de los objetivos de la reforma federal era potenciar el «federalismo competitivo» y con ello favorecer una mayor libertad de acción de los Länder a través de una separación más clara de competencias entre la Federación y los Länder que permitiera un deslinde (Entflechtung) respecto al enmarañamiento (Verflechtung) de la situación existente. En el punto de mira de la reforma, y para conseguir tales objetivos, se situaba la revisión de las tareas

29 R. STURm, «Zusammenarbeit im deutschen Föderalismus», op. cit., pp. 17-18; H. D. Jarass, B. Pieroth, «Art. 104b», Grundgesetz für die Bundesrepublik Deutschland. Kommentar, 14. Aufl., 2016, pp. 11481151. Específicamente sobre las ayudas financieras en el ámbito de la investigación, A. DitTmanN, Bildung und Wissenschaft in der bundesstaatlichen Kompetenzordnung, op. cit., pp. 96-102.

30 R. Schmidt-De Calluwe, «Art. 91a GG», en W. KLuth (Hrsg.), Föderalismusreformgesetz. Einfübrung und Kommentierung, Nomos, Baden Baden, pp. 216-217.

31 En la bibliografía española se ha seguido y estudiado con atención esta reforma del federalismo alemán: por todos, A. Arroyo GiL, La reforma constitucional del federalismo alemán, Institut d'Estudis Autonòmics, Barcelona, 2009. Asimismo, I. Gutiérrez Gutiérrez «Sentido y alcance de la reforma del federalismo alemán», Revista de Derecho Constitucional Europeo, n. ${ }^{\circ}$ 6, 2006, pp. 65-97; o C. ElíAs MÉNDEZ, «La reforma de la Constitución financiera en Alemania: una reforma pendiente», Revista de Derecho Constitucional Europeo, n. ${ }^{\circ}$ 6, 2006, pp. 223-252. 
comunes en cuanto emblema del grado más intenso de cooperación entre la Federación y los Länder, así como la reducción de la llamada financiación mixta entre ambas instancias ${ }^{32}$.

En materia de investigación, la reforma federal de 2006 ha tenido una notable incidencia ${ }^{33}$. Por un lado, dicha reforma ha suprimido la tarea común obligatoria en materia de ampliación y nueva construcción de centros de enseñanza superior prevista en el artículo 91a LFB desde 1969. Con base en dicha tarea común, se había llevado a cabo durante más de dos décadas la creación de edificios universitarios y otros centros de enseñanza superior, su dotación, así como las grandes instalaciones dedicadas a la investigación ${ }^{34}$.

La eliminación de esta tarea común, no sin polémica, se debió principalmente a uno de los leitmotiv de la reforma de 2006: retornar competencias a los Länder y favorecer, con ello, la libertad de acción de los mismos en un ámbito especialmente sensible para ellos porque, como indicado, la educación —y dentro de ella, la enseñanza superior - se enmarca en el ámbito de su soberanía cultural y se percibe como parte de su identidad regional. Con ello, y con la ya mencionada supresión también mediante esta misma reforma de la legislación marco de Federación en materia de enseñanza superior, este ámbito pasó a manos de los Länder. De este modo, se desapoderó a la Federación de competencias para intervenir en dicho sector (salvo en materia de acceso y títulos universitarios), con el consiguiente riesgo de disgregación del sistema de educación superior y para la movilidad de los estudiantes universitarios en el territorio federal ${ }^{35}$.

De mayor envergadura fue la profunda revisión que la reforma federal de 2006 llevó a cabo de la tarea común facultativa para la Federación y los Länder sobre planificación de la educación y fomento de la investigación. El artículo 91b LFB pasaba a quedar redactado como sigue:

32 F.W. SCHARpf, Föderalismusreform. Kein Ausweg aus der Politikverflechtungsfalle?, Campus, Frankfurt New York, 2009, pp. 100-116.

33 Sobre el estado de la cuestión y las propuestas en este ámbito en los trabajos parlamentarios de la Comisión conjunta del Bundestag y del Bundesrat para la modernización de las relaciones financieras entre el Bund y los Länder cuyas propuestas sirvieron de base para la reforma federal de 2006, vid. Die gemeinsame Kommission von Bundestag und Bundesrat zur Modernisierung der Bund-Länder-Finanzbeziehungen. Die Beratung und ibre Ergebnisse, Deutscher Bundestag, Bundesrat, Berlin, 2008, pp. 319-324, particularmente, pp. 319-322. Para una panorámica general del artículo 91b LFB resultante de la reforma. vid., J. HellermanN, «B. Gemeinschafsaufgaben (Art. 91a, 91b)», en C. STARCK (Hrsg.), Föderalismusreform. Einführung, C.H. Beck, Franz Vahlen, München, 2007, pp. 135-144.

34 R. W. MAIER, «Bildung und Forschung im kooperativen Föderalismus. Zu den Finanzierungskompetenzen des Bundes», Die Öffentliche Verwaltung, n. ${ }^{\circ}$ 56, 2003, p. 798. Dado el fuerte impacto de esta supresión, se ha introducido una regulación transitoria que prevé unas cantidades con cargo al presupuesto de la Federación, como compensación a los Länder por la supresión de esta tarea común desde el 1 de enero de 2007 hasta el 31 de diciembre de 2019 (art. 143c LFB). En desarrollo de la misma, se ha aprobado la correspondiente Ley federal de simplificación de las tareas comunes y de las ayudas financieras, de 5 de septiembre de 2006 [Gesetz zur Entflechung von Gemeinschaftsaufgaben und Finanzhilfen (Entflechtungsgesetz-EntfechtG) (BGB1. I S. 2098, 2102)].

35 A. Arroyo GiL, La reforma constitucional del federalismo alemán, op. cit., pp. 79-80. 
(1) La Federación y los Länder pueden cooperar en virtud de convenios en casos de alcance suprarregional en el fomento de:

1. instituciones y proyectos de investigación científica fuera de los centros de enseñanza superior;

2. proyectos de ciencia e investigación en centros de enseñanza superior;

3. edificios destinados a la investigación en centros de enseñanza superior, incluidas las grandes instalaciones de investigación.

Los convenios en virtud del apartado 1 número 2 requieren la aprobación de todos los Länder.

(2) La Federación y los Länder pueden cooperar en virtud de convenios para determinar la capacidad de rendimiento del sistema educativo en el marco de una comparación internacional, y en informes y recomendaciones al respecto.

(3) La carga de los gastos se regulará mediante convenio.

Dicho precepto se incluyó a instancias de los Ministros-Presidentes de la Unión Demócrata Cristiana, especialmente proclives a que las competencias educativas volvieran a manos de los Länder y a la supresión de la financiación de la Federación en ámbitos de aquellos ${ }^{36}$.

En ese sentido, la reforma de 2006 suprimió la planificación de la educación. Éste había sido un punto muy criticado, ya que en el seno de la Comisión para la planificación de la educación y del fomento de la investigación nunca se había podido aprobar un plan general educativo, debido a las profundas discrepancias políticas entre los Gobiernos de los Länder en este ámbito ${ }^{37}$. De este modo, la tarea común sobre planificación de la educación ya no existe y se ha reemplazado por la tarea común de evaluación del sistema educativo alemán en el marco de informes internacionales en lo que constituía una alusión velada a los Informes PISA — con fuerte eco en este país— que han mostrado grandes desniveles educativos entre los Länder alemanes ${ }^{38}$.

Específicamente, y por lo que respecta al ámbito que nos ocupa, la investigación, la reforma de 2006 mantuvo la tarea común en esta materia, si bien introdujo notables diferencias respecto a la redacción de 1969. Al igual que el anterior artículo 91b LFB, persistió la distinción entre «instituciones» (cooperación estable y permanente en el tiempo), y «proyectos» de investigación (una cooperación limitada temáticamente y en el tiempo).

$36 \mathrm{Al}$ respecto puede verse la entrevista a la entonces Ministra federal de Educación e Investigación, Dra. Annette Schavan: http://www.zeit.de/politik/deutschland/2009-12/schavan-bildung-foederalismus (consulta: 26.06.2016).

37 H. FABER, I. RiCHTER, «Art. 91a/ 91b», op. cit., p. 940; H.P. FüssEL, «Kooperativer Föderalismus im Bildungswesen», op. cit., p. 435.

38 Sobre esta tarea común, A. Guckelberger, «Leistungsmessungen im Bildungsbereich- eine neue Gemeinschaftsaufgabe?», en M. Seckelmann, S. Lange, T. Hortsmann (Hrsg.), Die Gemeinschaftsaufgaben von Bund und Länder in der Wissenschafts- und Bildungspolitik, Nomos, Baden-Baden, 2010, pp. 215-231. 
Sin embargo, la diferencia más importante estribó en que la reforma federal de 2006 diferenció el régimen de cooperación posible según se tratase de centros de investigación extrauniversitarios o de centros de enseñanza superior. En ese sentido, en el caso de los primeros (por ejemplo, las ya mencionadas sociedades y comunidades científicas en Alemania, como la Sociedad Max-Planck), se permitió la interacción entre la Federación y los Länder, tanto en instituciones, como en proyectos de investigación. Por el contrario, el fomento de la investigación en centros de enseñanza superior (y destacadamente Universidades) sólo se previó en el caso de proyectos y, con ello, sólo resultaba lícita constitucionalmente una cooperación temporal acotada y a un tema concreto.

La finalidad de introducir este tratamiento diferenciado fue limitar la influencia de la Federación, al impedirle participar en el fomento de la investigación institucional (a medio y a largo plazo e, independientemente, del tema de que se tratase) en los centros de enseñanza superior, un ámbito que la reforma de 2006 quiso devolver a manos de los Länder y, con ello, potenciar elementos competitivos entre ellos con vistas a incrementar su eficiencia ${ }^{39}$. La reforma de 2006 introdujo una particularidad adicional: los convenios sobre proyectos de investigación en el caso de los centros de investigación superior debían ser aprobados por unanimidad de todos los Länder.

Dicha reforma introdujo un tercer apartado en el artículo 91b 1. LFB donde se contempló la posibilidad de cooperación entre la Federación y los Länder en el caso de los «edificios de investigación en los centros de enseñanza superior, incluidas las grandes instalaciones dedicadas a la investigación». A través de esta previsión, la reforma de 2006 pretendió compensar la desaparición de la tarea común obligatoria relativa a la ampliación y nueva construcción de centros de enseñanza superior, antes ya indicada. De esta manera, la reforma de 2006 convirtió en facultativa una cooperación que, antes de la misma, era obligatoria en ese ámbito y, con ello, también se amplió la libertad de los Länder en todos esos casos.

El artículo 91b LFB en la redacción resultante de la reforma federal de 2006 previó un último apartado donde se dispuso que un convenio regularía quién debía soportar los gastos de las tareas comunes previstas en dicho precepto. Respecto a la reforma de 1969, esa redacción contempló una novedad importante. El primer tenor del artículo 91b LFB hablaba de «reparto de gastos», de tal manera que éstos debían asumirse por la Federación y los Länder. Sin embargo, tras la reforma de 2006, los gastos podían asumirse por una sola instancia, la Federación, o bien los Länder, no necesariamente por ambas instancias como se previó anteriormente ${ }^{40}$.

La articulación orgánica de la cooperación para el fomento de la investigación tras la reforma de 2006 corresponde a la Conferencia conjunta en materia de

39 M.-E. Geis, D. Krausnick, «Das Hochschulrecht im föderalen System der Bundesrepublik», op. cit., p. 287.

40 H. D. Jarass, B. Pieroth, «Art. 91b», Grundgesetz für die Bundesrepublik Deutschland. Kommentar, 11. Aufl., C.H. Beck, München, 2011, p. 935. 
Ciencia (Gemeinsame Wissenschaftskonferenz-GWK) que sustituye a la Comisión Bund-Länder para la planificación de la educación y el fomento de la investigación (BLK) desde el 1 de enero de 2008. Esta nueva Conferencia sectorial se ocupa, tras la supresión de la tarea común sobre planificación de la educación, específicamente de la coordinación de la política en materia de investigación, tanto en el ámbito nacional, como europeo e internacional, con el objetivo de incrementar la competitividad y el liderazgo científico de Alemania en un mundo globalizado. El objeto del fomento conjunto de la investigación son los centros de enseñanza superior, así como los centros extrauniversitarios ${ }^{41}$.

Se trata de una Conferencia con una constitución expresamente vertical, esto es, está formada por los Ministros de Finanzas y de Investigación de la Federación y de todos los Länder. Ello constituye una singularidad en el sistema alemán donde normalmente las Conferencias intergubernamentales son formalmente horizontales, y, por tanto, de los Länder. En el seno de esta Conferencia, la Federación y los Länder suman cada uno 16 votos. Al igual que su predecesora, la regla de decisión es la mayoría cualificada ${ }^{42}$. Las resoluciones de la Conferencia pueden hacerse vinculantes con la aprobación de los Jefes de Gobierno de la Federación y de los Länder para las partes suscriptoras ${ }^{43}$. Las actuaciones propuestas y, en su caso, negociadas en el seno de esta Conferencia se financian de acuerdo con la mencionada fórmula de Könisgsteiner que cada año actualiza y publica dicha Conferencia ${ }^{44}$.

\section{LA REFORMA DE 2014}

Pocas disposiciones de la Ley Fundamental de Bonn han sido tan duramente criticadas como el artículo 91b 1 . LFB resultante de la gran reforma federal de 2006. Dicha regulación ha sido valorada como «disparate», «absurda», «la apuesta política más descabellada de los últimos tiempos» ${ }^{45}$, «contraproducente», o «error político grave» ${ }^{46}$.

41 Anexo al Convenio por el que se crea la Conferencia conjunta de la Ciencia [Anlage zum GWK-Abkommen http://www.gwk-bonn.de/fileadmin/Papers/gwk-abkommen.pdf (consulta: 26.06.2016)].

42 Para adoptar una resolución se precisan 29 votos, lo que significa que son necesarios los votos de la Federación y 13 de los 16 Länder (art. 4.4 Convenio por el que se crea la Conferencia conjunta de la Ciencia).

43 Art. 4.6 Convenio por el que se crea la Conferencia conjunta de la Ciencia.

44 H.-G. Husung, «Die Gemeinsame Wissenschaftskonferenz (GWK)»: http://www.gwk-bonn.de/ die-gwk/aufgaben/die-gwk-handbuch/ (consulta: 26.06.2016). Los porcentajes concretos resultantes de la fórmula de Königsteiner para el periodo 2010-16, en http:/www.gwk-bonn.de/fileadmin/Papers/koenigsteiner-schluessel-2010bis2016.pdf (consulta: 26.06.2016).

45 G. Speiser, «Das Kooperationsverbot-Status quo und Handlungsoptionen», Die Öffentliche Verwaltung, 2014, n.18, p. 555 .

46 Respectivamente, en M.-E. Geis, D. Krausnick, «Das Hochschulrecht im föderalen System der Bundesrepublik», op. cit., p. 290; M.-E. GEIS, «Das «Kooperationsverbot» des Art. 91b GG: oder: Die bildungspolitische Büchse der Pandora», Zeitschrift für Gesetzgebung, n. ${ }^{\circ}$ 4, 2013, p. 313. 


\section{Las causas, el contexto y la génesis de la reforma}

\section{A) Las consecuencias de la reforma federal de 2006 en materia de investigación: crónica de un error constitucional anunciado}

Las dramáticas consecuencias que para la financiación de la investigación (especialmente, en las Universidades) representaba el artículo 91b 1. LFG tras la reforma de 2006 han sido la causa de su reformulación en 2014. La regulación del artículo 91b 1. LFB en 2006 consagraba básicamente una prohibición de cooperación entre el Bund y los Länder que suponía un obstáculo para la financiación conjunta de una investigación institucional y estable en el ámbito de la enseñanza superior. Cómo eliminar esa prohibición de cooperación y sobre todo cuándo debía poder llevarse a cabo su supresión han sido las cuestiones que han dominado el debate que ha precedido a esta reforma.

La llamada "prohibición de cooperación» (das Kooperationsverbot) no se halla formulada explícitamente como tal en la Ley Fundamental de Bonn, sino que es una expresión que ha ocupado un lugar central en la reforma federal de 2006. El origen de esa prohibición se suele ubicar en el nuevo artículo 104b LFB resultante de la reforma de 2006 (anterior art. 104a.4 LFB) y relativo a las ayudas financieras que la Federación puede conceder a los Länder en los supuestos antes vistos. Dichas ayudas federales tras la reforma de 2006 sólo se pueden conceder «en la que medida en que esta Ley Fundamental le otorgue competencias legislativas». Esa limitación a las ayudas financieras de la Federación se ha bautizado como la prohibición de cooperación, una expresión que ha hecho fortuna y que ha servido también para referirse a los casos en los que se permite esa cooperación entre la Federación y los Länder en el ámbito de la investigación y, a sensu contrario, los supuestos en los que no cabe la misma ${ }^{47}$.

El alcance del artículo 91b.1 LFB resultante de la reforma federal de 2006 debe enmarcarse en el escenario normativo que creó dicha reforma: la Federación había perdido la competencia sobre legislación marco en la reforma federal de 2006 en materia de enseñanza superior y, con ello, el instrumento normativo más potente para regular las Universidades en el sistema alemán. Además, la reforma de 2006 también desapoderó a la Federación de la posibilidad de intervenir financieramente en dicho sector, pues modificó sustancialmente el régimen de la cooperación financiera que se articulaba a través de las ayudas financieras en el nuevo artículo 104b LFB, lo que había supuesto la supresión de las ayudas federales en materia de enseñanza (donde se incluyen las Universidades y los centros de enseñanza superior, pilares de la investigación). De este modo, con esa prohi-

47 Sobre la discusión acerca de dónde ubicar la llamada prohibición de cooperación, M. SECKELMANN, «Das sog. "Kooperationsverbot" und die Mittel zu seiner Behebung», Die Öffentliche Verwaltung, n. ${ }^{\circ}$ 18. 2012, p. 701; H.-G. Henneke, «Art. 91b», en B. Schmidt-Bleibtreu, H. Hoffmann, H.-G. Henneke (Hrsg.), Kommentar zum Grundgesetz, 13. Aufl., 2014, Carl Heymanns Verlag, Köln, p. 2148. 
bición de cooperación, la Federación sólo podía participar y dar dinero a la investigación en las Universidades a través de programas singulares. Por su parte, y consiguientemente, los Länder se encontraban con una creciente sobrecarga financiera ${ }^{48}$.

Si en la tramitación parlamentaria de la reforma de 2006 no se hubiera incluido in extremis en el artículo 91b 1. LFB la referencia al fomento de "proyectos de la ciencia y de la investigación en los centros de enseñanza superior», se hubiera eliminado prácticamente cualquier financiación federal en estos $\operatorname{casos}^{49}$.

Sin embargo, el artículo 91b.1 LFB, en la redacción dada por la reforma de 2006, abrió «la caja de pandora ${ }^{50}$ al establecer una doble diferenciación: por un lado, el objeto del fomento de la investigación («proyectos»e «instituciones»); y, por otro, el tipo de centro investigador, («centros de enseñanza superior» y los centros extrauniversitarios).

El artículo 91b.1 LFB previó la cooperación financiera entre la Federación y los Länder para promover la investigación tanto de proyectos, como de instituciones extrauniversitarias, mientras que en el ámbito de los centros de enseñanza superior - para evitar el riesgo de la influencia federal por la vía financiera en un ámbito recuperado para los Länder - sólo se permitió esa cooperación para proyectos, mientras que la prohibió en el caso de instituciones de investigación: esto es, se vetaba una cooperación financiera sostenida en el tiempo en tales supuestos.

Ello provocaba graves efectos para la sostenibilidad de la investigación en las Universidades, así como para la calidad de la misma, pues «programas limitados temporalmente y, con ello, una financiación también limitada temporalmente, no son suficientes para conseguir un estándar y una calidad [...] que pueden conseguirse de una forma permanente $»^{51}$.

Ante esa situación, la prohibición de cooperación en materia de enseñanza superior no sólo era un tema criticado por la doctrina, sino que empezó crear pronto conflictos reales graves. Los Länder alemanes — con muchas competencias, pero recursos financieros claramente inferiores a los de la Federación- se veían sobrepasados para asumir proyectos e instituciones de investigación que resultaban sumamente costosos. Muy ilustrativo, y muy controvertida jurídicamente fue la intervención de la Federación cuando «rescató» a la Facultad de

48 Sobre las consecuencias de las reforma de 2006 en el campo de la investigación, una completa exposición en W. KLUTH, «Die Auswirkungen der Neufassung von Art. 91b Absatz 1 GG auf die Wissenschaftsförderung in Deutschland», Recht der Jugend und des Bildungswesens, n. ${ }^{\circ}$ 3, 2008, pp. 255-282.

49 En las negociaciones algunos Länder (en particular, los financieramente más fuertes) querían eliminar a la Federación de la educación superior, de modo que hubo al final una «operación de salvamento" que permitió a la Federación financiar los proyectos en dichos centros, vid. M. SECKELmann, «Das sog. "Kooperationsverbot" und die Mittel zu seiner Behebung», op. cit., p. 703.

50 En expresisón de M.-E. GeIs en su trabajo, «Das "Kooperationsverbot” des Art. 91b GG: oder: Die bildungspolitische Büchse der Pandora», op. cit., p. 307.

51 Empfehlungen der Ausschüsse. Bundesrat Drucksache 323/1/14 p. 3. 
Medicina de Lübeck, cuyos gastos el Land debía sufragar, pero no podía asumir ${ }^{52}$. Con el marco constitucional resultante de la reforma de 2006, cuando un Land más débil financieramente no podía sufragar un centro de investigación, resultaba muy difícil que la Federación pudiera salir al frente, salvo recurriendo a argucias jurídicas que bordeaban la inconstitucionalidad. De esta manera, con los problemas surgieron dudosos atajos para resolverlos.

Por un lado, y ante la imposibilidad de que la Federación pudiera financiar junto a los Länder programas que fomentaran instituciones de investigación y, con ello, una investigación duradera y a largo plazo, la Federación impulsó programas que, en realidad, preveían un fomento encubierto de la investigación institucional en el ámbito universitario.

El artículo 91b.1 LFB tras la reforma de 2006 ha sido la base constitucional que ha amparado los grandes programas que en la pasada década han sido presentados como proyectos.

Entre ellos, destacaron una serie de grandes programas en la política cooperativa en materia de investigación: la Iniciativa para la Excelencia (Exzellenziniciative), a través de la cual se pretendía fomentar una investigación de élite a medio plazo; el Pacto por la Investigación y la Innovación (Pakt für Forschung und Innovation), que aumentaba el presupuesto de los grandes centros de investigación extreuniversitarios alemanes, el Pacto por los Centros de Enseñanza Superior (Hochschulpakt), que pretendía hacer frente al incremento de estudiantes universitarios; o el Pacto por la Calidad de la Enseñanza universitaria (Qualitätspakt Lebre) para mejorar la selección, formación y apoyo al profesorado ${ }^{53}$. El caso más polémico ha sido la llamada Iniciativa para la Excelencia investigadora, que se puso en marcha en 2005. Dicho programa suscitaba serias dudas acerca de su constitucionalidad, ya que iba más allá del diseño y financiación de los meros proyectos temporal y temáticamente limitados que permitía la Constitución tras la reforma de $2006^{54}$.

Por otro lado, el artículo 91b LFB, tras dicha reforma, no permitía, o por lo menos, no lo hacía de forma clara, la cooperación entre centros de enseñanza superior, en particular Universidades, y centros de investigación extrauniversitarios.

A pesar de que esa opción se había recomendado como una alternativa solvente para promover una investigación de calidad, el fomento de la cooperación

52 Sobre este episodio: http://www.spiegel.de/unispiegel/studium/luebecker-medizinstudium-wie-schavan-die-uni-rettung-herbeitrickste-a-705473.html (consulta: 26.06.2016).

53 Sobre estas iniciativas y la ejecución de la reforma federal en este ámbito, en especial, H.-P. SCHNEIDER, Der neue deutsche Bundesstaat. Bericht über die Umsetzung der Föeralismusreform I, Nomos, Baden Baden, 2013, pp. 147-153.

54 M.-E. Geis, D. Krausnick, «Das Hochschulrecht im föderalen System der Bundesrepublik», op. cit., pp. 289-290. Específicamente, S. SiEweKe, «Verfasssungsrechtliche Anforderungen an die Fortsetzung der Exzellenzinitiative», Die Öffentliche Verwaltung, n. ${ }^{\circ} 22,2009$, en particular pp. 946-948. 
entre Universidades y centros extrauniversitarios se veía como una vía encubierta de influencia indirecta de la Federación en la enseñanza superior (de nuevo, en manos de los Länder, tras la reforma de 2006) a través de los centros extrauniversitarios que sí podían contar con financiación federal. En ese sentido, resultó muy polémica, la constitución del Instituto de Tecnología de Karlsruhe en 2009, uno de los centros de investigación más prestigiosos de Alemania en materia de ingeniería y ciencias naturales, constituido de la unión entre la Universidad Técnica de Karlsruhe y el Centro de Investigación de Karlsruhe (adscrito a un centro extrauniversitario, como la Comunidad Helmholtz) $)^{55}$.

\section{B) Intentando corregir el error: a la espera de una mayoría favorable para la reforma constitucional}

La prohibición de cooperación en el ámbito de la investigación se introdujo en la Ley Fundamental de Bonn, de modo que, si la solución pasaba por suprimirla, era necesaria una nueva reforma constitucional. Sin embargo, la ansiada reforma ha tardado en llegar casi una década hasta que se ha abierto, de nuevo, la ventana de la oportunidad política para la misma.

a) El fallido proyecto de reforma de 2012

La segunda etapa de la reforma federal en 2009 (Föderalismusreform II) no pudo aprovecharse para enmendar el error que supuso la aprobación del artículo $91 \mathrm{~b}$ 1. LFB en 2006. En 2011, en el Bundestag, se habían presentado mociones a favor de suprimir la prohibición de cooperación entre el Bund y los Länder en el ámbito educativo por parte de los grupos parlamentarios que estaban en la oposición (el partido socialdemócrata, SPD, los antiguos comunistas, La Izquierda, Die Linke, y los ecologistas, Bündnis 90/Die Grünen) ${ }^{56}$. En el Bundesrat, los Länder de Schleswig-Holstein y Hamburgo se manifestaron también en ese sentido ${ }^{57}$.

Sin embargo, el primer proyecto de reforma constitucional para suprimir la prohibición de cooperación entre la Federación y los Länder en el campo de la

55 Sobre estos casos, J. WolfF, «Der neue Artikel 91b GG - Erweiterte Kooperation im Wissenschaftsföderalismus», Die Öffentliche Verwaltung, n. ${ }^{\circ} 18,2015$, p. 775.

56 SPD: Deutscher Bundestag Drucksache 17/5911, 17/4187, 17/4018; Die Linke: Deutscher Bundestag Drucksache 17/6094, Bündnis90/Die Grünen: Deutscher Bundestag, Drucksache 17/8902. Las diferentes mociones pueden consultarse en https://www.bundestag.de/dokumente/textarchiv/2011/34734736_ kw23_de_bildungszusammenarbeit/205664 (consulta: 27.06.2016).

57 La moción de Schleswig-Holstein en el Bunderat, Drucksache 43/12, y la moción de Hamburgo también en el Bundesrat, Drucksache 63/12. 
investigación se presentó por un Gobierno de coalición entre la democracia cristiana y el partido liberal (CDU/CSU-FDP), en concreto, se impulsó, por la entonces Ministra federal de Educación e Investigación, la Dra. Annette Schavan, de la Unión Demócrata Cristiana (CDU). Justamente, durante su mandato se habían promovido varios proyectos en el campo de la investigación, entre ellos la ya mencionada Iniciativa para la Excelencia investigadora, y habían empezado a aflorar los graves problemas que creaba el marco constitucional resultante de la reforma de 2006 para una intervención financiera de la Federación en el ámbito de la investigación especialmente en las Universidades.

El 20 de julio de 2012, el proyecto de reforma constitucional se presentó en el Bundesrat. Se trataba de una modificación de mínimos donde se proponía que el artículo 91b 1. LFB en su apartado segundo se incorporase la palabra «instituciones». El futuro artículo 91b 1. LFB debía permitir el fomento de «proyectos e instituciones de ciencia e investigación en los centros de enseñanza superior» [la cursiva es mía]. Con ello, se pretendía ampliar la cooperación entre la Federación y los Länder no sólo en proyectos (temporales), sino también con una cooperación institucional (permanente y a largo plazo), al igual que se prevé para los centros extrauniversitarios ${ }^{58}$.

En el Bundesrat, la mayoría era justamente de los Länder gobernados por la socialdemocracia y los ecologistas (la contraria a la existente en el Bundestag), así que el proyecto de reforma no consiguió, el 21 de septiembre de 2012, la mayoría de dos terceras partes que precisaba de la Cámara territorial. Las fuerzas políticas dominantes en el Bundesrat rechazaron la reforma arguyendo que la supresión de la prohibición de cooperación debía hacerse en todo el ámbito educativo y no sólo en un segmento del mismo, en el sector de investigación, tal y como propugnaba el proyecto ${ }^{59}$.

Las posiciones de los partidos políticos sobre la supresión de la prohibición de cooperar eran claras y enconadas. El partido socialdemócrata (SPD), los verdes (Bündnis 90/Die Grünen) y La Izquierda (Die Linke), habían manifestado que no aceptarían ninguna solución parcial, sino su supresión en todo el sector educativo para conseguir fondos federales no sólo para las Universidades, sino también para escuelas y guarderías. Por el contrario, la democracia cristiana (CDU, y muy especialmente la CSU, su equivalente en Baviera) defendían una reforma de mínimos para lograr dinero federal exclusivamente para investigación y la menor influencia posible de la Federación en el ámbito educativo ${ }^{60}$.

58 Bundesrat Drucksache 419/12.

59 Deutscher Bundestag Drucksache 17/10956, Stellungnahme des Bundesrates, p. 9.

60 La posición del partido bávaro era meridiana: se niega a recibir dinero de Berlín, porque no se puede ser tan ingenuo de creer que la Federación da dinero a cambio de nada. «La educación en manos de los Länder está en buenas manos», Geld aus Berlin?: Nein danke! http://www.bayerische-staatszeitung.de/staatszeitung/politik/detailansicht-politik/artikel/geld-aus-berlin-nein-danke.html (consulta: 27.06.2016). 
b) Las elecciones federales de 2013, de nuevo una gran coalición y, por fin, llega la mayoría para la reforma de 2014

Un año después, el 22 de septiembre de 2013 se celebraron elecciones federales que propiciaron la tercera gran coalición entre la democracia cristiana y la socialdemocracia (CDU/CSU-SPD). Con ello, se abrió la ventana de la oportunidad para sumar las dos terceras partes que eran necesarias para la aprobación de una reforma constitucional, tanto en el Bundesrat, como en el Bundestag.

En el pacto de coalición entre los dos grandes partidos no se mencionó en ningún momento la reforma de la Ley Fundamental de Bonn en este punto, si bien la supresión de la prohibición de cooperación entre la Federación y los Länder había estado presente en la campaña electoral y resultaba difícilmente compresible para la opinión pública comprender por qué ambas instancias no podían cooperar en cuestiones centrales de la política educativa en general, e investigadora, en particular.

Con una mayoría más favorable que en la legislatura anterior, el Gobierno federal presentó, el 18 de julio de 2014, un nuevo proyecto de reforma constitucional, a instancias de la nueva Ministra federal de Educación e Investigación, la Profesora Johanna Wanka (al igual que su antecesora de la CDU), sobre el artículo $91 \mathrm{~b} 1 \mathrm{LFB}$ cuyo tenor era el siguiente ${ }^{61}$ :

«(1) La Federación y los Länder pueden cooperar en virtud de convenios en casos de alcance suprarregional en el fomento de la ciencia, la investigación y la enseñanza científica. Los convenios que afecten en su esencia a los centros de enseñanza superior precisan la aprobación de todos los Länder. Ello no rige para los convenios sobre edificios destinados a la investigación en los centros de enseñanza superior, incluidas las grandes instalaciones de investigación».

El Bundesrat — con una mayoría ahora de Länder gobernados por los partidos de la gran coalición - saludó la iniciativa del Gobierno federal que ampliaba las posibilidades de cooperación entre la Federación y los Länder en el ámbito de la investigación, pero subrayó que el carácter parcial de esta reforma (sólo en investigación) no debía soslayar «la existencia de grandes retos en el conjunto del ámbito educativo y, por ello, en el futuro, también en ese ámbito son necesarias nuevas formas de cooperación y un compromiso más fuerte de la Federación» ${ }^{62}$.

Ante la objeción de que la reforma dejaba fuera la educación escolar, el Gobierno federal en su réplica anunció una nueva reforma de la Ley federal para el fomento de ayudas a la formación (Bundesausbildungsförderungsgesetz-BAföG), que descargaba a los Länder y sus finanzas de los gastos en ese ámbito, ya que la Federación aportaría más de miles de millones de euros al año en ese concepto (en

61 Bundesrat Drucksache 323/14.

62 Deutscher Bundestag Drucksache 18/2710 Anlage 2 p. 8. 
concreto, un ahorro de 1,2 mil millones de euros anuales). En ese sentido, la reforma constitucional del artículo $91 \mathrm{~b} 1$. LFB se ha planteado como un paquete global $^{63}$ y el consentimiento a la reforma por parte de los Länder se premia con un gran regalo, pues los Länder ya no deberán asumir los gastos de la ley federal para el fomento de ayudas a la formación.

Durante su tramitación en el Bundestag, los Grupos parlamentarios La Izquierda (Die Linke) y los ecologistas (Bündnis 90/Die Grünen), muy activos en la supresión de la prohibición de cooperación en todo el sector educativo, presentaron sendas enmiendas. Además de ello, los primeros propusieron la inserción en la Ley Fundamental de una nueva tarea común en materia de educación ${ }^{64}$. Por su parte, los ecologistas también reclamaron la posibilidad de que la Federación y los Länder cooperaran en el sector educativo en general. Además, criticaron el hecho de que el procedimiento de la reforma se hubiera vinculado a la reforma de la Ley federal para el fomento de ayudas a la formación y a ese do ut des que representó la aceptación de la reforma a cambio de descargar financieramente a los Länder en dicha ley en los términos vistos ${ }^{65}$. La Comisión de Educación, Investigación y Evaluación del Impacto Tecnológico del Bundestag, tras la comparecencia de especialistas de reconocido prestigio en este ámbito, defendió la reforma constitucional propuesta ${ }^{66}$.

El Bundestag aprobó dicha reforma en los mismos términos que había presentado el proyecto del Gobierno federal, el 13 de noviembre de 2014, con el voto favorable de la coalición entre la Unión Demócrata Cristiana (CDU/ CSU) y el Partido Socialdemócrata (SPD). La Izquierda (Die Linke) votó en contra y los ecologistas (Bündnis 90/Die Grünen) se abstuvieron. Por su parte, el Bundesrat votó a favor de la reforma, el 19 de diciembre de 2014, y la reforma constitucional quedó aprobada en menos de seis meses desde su presentación: el 23 de diciembre de 2014. Tras su publicación el último día de 2014, la 60. ${ }^{a}$ reforma constitucional de la Ley Fundamental de Bonn entró en vigor el 1 de enero de $2015^{67}$.

63 Deutscher Bundestag Drucksache 18/2710, Anlage 3 Gegenaüßerung der Bundestregierung p. 10. La tramitación de la reforma y del proyecto de ley en el mismo orden del día, Bundesrat Plenarprotokol II 925 p. 271 (B). http://www.bundesrat.de/SharedDocs/downloads/DE/plenarprotokolle/2014/Plenarprotoko11-925.pdf?_blob=publicationFile\&v=2 (consulta: 26.06.2016).

64 Antrag der Fraktion Die Linke Deutscher Bundestag Drucksache 18/588.

65 Antrag der Fraktion Bündnis90/Die Grünen Deutscher Bundestag Drucksache 18/2747.

66 En la Comisión comparecieron: el Servicio de Intercambio Académico Alemán DAAD, el Secretariado de la Conferencia Sectorial de Cultura de los Länder (KMK), el Consejo de Investigación (WR), la Profesora Margrit Seckelmann del Instituto alemán de Investigación sobre la Administración Pública de Speyer, el Profesor Max-Emanuel Geis, de la Friedrich-Alexander-Universität Erlangen-Nürnberg, el Profesor Hans-Günter Henneke, del Deutscher Landkreistag, el Sindicato de Educación e Investigación (GEW), la Conferencia de Rectores de los Centros de Enseñanza Superior (HRK) y el Profesor Wolfgang Löwer de la Universidad de Bonn. Dichas comparecencias pueden consultarse en: https:/www.bundestag.de/bundestag/ ausschuesse18/a18/anhoerung-gg-91b/337000 (consulta 27.06.2016).

67 BGB1. I 2014, p. 2438. 


\section{El objetivo y el contenido de la reforma: el nuevo artículo 91b LFB}

A la vista de lo expuesto, resulta ya meridiano que el objetivo de la reforma de 2014 ha sido ampliar la posibilidad de cooperación del Bund y los Länder para poder financiar conjuntamente la investigación en los centros de enseñanza superior en cuanto pieza clave para consolidar a Alemania como país investigador competitivo a escala mundial. Y, a la par, ha dado una mayor estabilidad en el contexto nacional e internacional a la investigación que se desarrolla en estos centros y, en especial, a las Universidades, pues el conocimiento científico se valora como un elemento decisivo de crecimiento y bienestar ${ }^{68}$. Con ello, se ha derogado la llamada prohibición de cooperar en dichos ámbitos, prohibición que había sido uno de los eslóganes de la reforma federal de 2006.

\section{A) Materialmente: la Federación vuelve a contar con un apoderamiento constitucional en investigación (y muy amplio)}

El constituyente disponía de varias opciones técnicas para conseguir esa mayor financiación (y, en particular, la financiación federal). Por un lado, podía haberse planteado un incremento de la participación de los Länder en el impuesto sobre el valor añadido. Asimismo, cabía la posibilidad de reformar las ayudas financieras del artículo $104 \mathrm{~b}$ LFB para permitir transferencias de la Federación a los Länder específicamente en enseñanza superior e investigación. Sin embargo, la reforma de 2014 (y también el proyecto previo de 2012) ha optado por ampliar una tarea común: la tarea común del artículo 91b 1. LFB $^{69}$.

La opción por afianzar una tarea común significa que se ha elegido la alternativa que da más poder a la Federación. Como indicado, las tareas comunes representan una excepción al ejercicio de las competencias asumidas por cada instancia por separado (art. 30 LFB), así como al principio de conexidad, según el cual paga quien tiene la competencia (art. 104a LFB). Se trata también de la técnica de cooperación vertical más intensa y a través de la cual la Federación aporta financiación, pero a cambio gana un poder de decisión y una influencia adicionales en enseñanza superior e investigación, ámbitos principalmente de los Länder y donde la Federación tiene muy pocas competencias ${ }^{70}$. No obstante, debe recordarse que el artículo 91b 1. LFB es una tarea común facultativa y, por tanto, no impo-

68 Bundesrat Drucksache 323/14, p. 2.

69 El Gobierno federal en la Motivación al Proyecto de reforma: «A través de la reforma de la Ley Fundamental de Bonn se amplían las posibilidades de cooperación del Bund y los Länder en el marco de una tarea común» [Bundesrat Drucksache 323/14 p. 2]. Sobre las otras posibles opciones, M. SECKELMANN, «Bildung und Wissenschaft im Bundesstaat», op. cit., p. 85.

70 A. Kienemund, «Artikel 91b», en D. Hömig, H. A. WolfF (Hrsg.), Grundgesetz für die Bundesrepublik Deutschland, 11. Aufl, Nomos, Baden Baden, 2016, pp. 664-666. 
ne una obligación de actuación conjunta, sino que sólo permite a la Federación y a los Länder la posibilidad de interactuar en este ámbito, por lo que remite, así, al pacto político.

El nuevo artículo 91b 1. LFB no sólo da poder a la Federación, sino que da más poder que nunca a la Federación en materia de enseñanza superior e investigación. Por tanto, la reforma no sólo amplía las posibilidades de cooperación entre la Federación y los Länder respecto a la restricción que supuso la reforma federal de 2006, sino que va más allá de las previsiones iniciales que se introdujeron en 1969 en este punto.

El párrafo primero del nuevo artículo 91b LFB prevé en su primer inciso que: «La Federación y los Länder pueden cooperar en virtud de convenios en caso de alcance suprarregional en el fomento de la ciencia, la investigación y la enseñanza científica». No hay novedades respeto al presupuesto que la Ley Fundamental de Bonn exige desde 1969 para que la Federación y los Länder puedan fomentar conjuntamente la investigación: los casos «de alcance suprarregional» («überregionaler Bedeutung») de las actuaciones a fomentar. El «alcance suprarregional» existe cuando el objeto de fomento tiene una «capacidad de irradiación más allá del alcance de un solo Land y resulta significativo en el contexto nacional $\mathrm{o}$ internacional» ${ }^{71}$.

La apreciación de que existe ese alcance suprarregional queda en manos de la Federación y los Länder que disponen, de este modo, de una amplia libertad para concretar dicho presupuesto en los convenios donde deben articularse las actuaciones a fomentar conjuntamente entre ambos ${ }^{72}$. Entre los indicios de significado suprarregional se barajan: la magnitud financiera de las actuaciones objeto de fomento, en qué medida dichas actuaciones repercuten en estudiantes de distintos Länder, o bien si el objeto de fomento está ligado también a financiación internacional ${ }^{73}$.

La principal novedad que incorpora el nuevo artículo 91b LFB desde el punto de vista material, y donde se apodera enormemente a la Federación, radica en que incorpora una formulación unitaria para designar qué puede ser objeto de esa tarea común: «el fomento de la ciencia, la investigación y la enseñanza científica». Esa formulación general es la que legitima la intervención de la Federación en investigación, como nunca antes lo había hecho la Ley Fundamental de Bonn.

La referencia a «fomento» (Förderung) incluye, como en las redacciones anteriores, no sólo financiación, sino también actuaciones organizativas y de planificación. El nuevo tenor elimina cualquier distinción entre «proyectos»e «instituciones» de investigación que introdujo la reforma de 1969 —y que

71 Así consta en la propia Motivación al Proyecto de reforma: Bundesrat Drucksache 323/14.

72 R. P. Schenke, «Art. 91b», en H. Sodan (Hrsg.), Gundgesetz, 3. Aufl., C.H. Beck, München, 2015 , p. 599.

73 J. WolfF, «Der neue Artikel 91b GG - Erweiterte Kooperation im Wissenschaftsföderalismus», op. cit., p. 777. 
mantuvo la reforma de 2006 - y la sustituye por una mención a «la ciencia, la investigación y la enseñanza científica» (Wissenschaft, Forschung und Lebre) como objeto de fomento, lo que ha abierto considerablemente las posibilidades de cooperación entre ambas instancias. Asimismo, esta nueva redacción ha suprimido el catálogo de actuaciones que podían acometer conjuntamente la Federación y los Länder en función de si se trataba de un centro de enseñanza superior, o bien un centro extrauniversitario, tal como que había introducido la reforma de 2006 (a recordar, proyectos e instituciones en centros extrauniversitarios, art. 91b 1.1 LFB; sólo proyectos en el caso de centros de enseñanza superior, art. 91b.1.2 LFB; y edificios destinados a la investigación en estos centros, art. 91b.1.3 LFB).

De esta manera, con el nuevo artículo 91b 1. LFB se han eliminado los problemas que planteaba la redacción dada a este precepto por la gran reforma federal de 2006. Esta nueva previsión constitucional permite el fomento conjunto por parte de la Federación y los Länder de la investigación, tanto en centros de enseñanza superior, como en centros extrauniversitarios, y tanto de proyectos, como de instituciones científicas. Consiguientemente, la reforma de 2014 permite la financiación conjunta (y con ello, la financiación y la intervención federal) en la investigación institucional —a largo plazo y permanente- también en los centros de enseñanza superior, no sólo en los centros extrauniversitarios, como había previsto el texto anterior con la intención de reducir a su mínima expresión la presencia federal en el ámbito de la educación superior. Además, esa equiparación entre centros de enseñanza superior y centros extrauniversitarios en cuanto a la financiación conjunta (y, con ello, de la Federación) tiene una gran relevancia práctica, ya que también abre la puerta a la cooperación entre ambos tipos de centros tan cuestionada con la redacción anterior.

Esa nueva formulación del artículo 91b 1. LFB donde se posibilita la cooperación entre la Federación y los Länder para el fomento de «la ciencia, la investigación y la enseñanza científica» no ha estado tampoco exenta de polémica. La doctrina absolutamente dominante considera que «ciencia» (Wissenschaft) es un supraconcepto donde se engloban tanto la «investigación» (Forschung), en cuanto «actividad intelectual orientada a generar nuevos conocimientos de una forma metódica, sistemática y verificable», como la enseñanza científica (Lebre $)^{74}$, en tanto que «transmisión de los conocimientos adquiridos mediante la investigación» ${ }^{75}$. Por ello, esta nueva redacción se ha calificado como "pleonasmo», pues

74 El término Lebre se ha traducido como «enseñanza científica» para diferenciarlo del más genérico de enseñanza, siguiendo la traducción al español de la Ley Fundamental de Bonn (artículo 5.3 LFB), editada por el propio Bundestag y a cargo de los Profesores Ricardo García Macho y Karl-Peter Sommermann (última actualización octubre de 2010).

75 BVerfGE 35, 79 (113) (Hochschul-Urteil). Asimismo, sobre el ámbito de protección de la libertad de investigación (Freibeit der Wissenschaft) incluyendo investigación (Forschung) y enseñanza (Lehre), H. D. 
en «ciencia», en el sentido que utiliza la Ley Fundamental de Bonn, se englobarían ya los otros dos términos ${ }^{76}$.

La referencia a la «enseñanza científica» como objeto de fomento, junto a la ciencia y la investigación, es una novedad que introduce por primera vez la reforma de 2014 en el artículo 91b LFB. Hasta ese momento la Ley Fundamental de Bonn sólo se refería a este tipo de enseñanza en el marco de la libertad de investigación (art. 5.3 LFB). Sin embargo, a pesar de que esta mención no estaba en las versiones anteriores, su omisión no ha sido obstáculo para entender que quedaba dentro del término «ciencia». Con esta referencia a la enseñanza, la reforma de 2014 no introduce una novedad sustantiva, sino que propiamente pretende dejar claro algo que ya se entendía de forma implícita ${ }^{77} \mathrm{y}$, posiblemente, da visibilidad a uno de los ámbitos donde va a ser más necesario invertir en atención al importante incremento de estudiantes que acceden a las Universidades alemanas ${ }^{78}$. Dicha mención carece, pues, de efectos prácticos y se va a referir sobre todo a la enseñanza en los centros de enseñanza superior, pues la docencia académica tiene un peso poco relevante en los centros de investigación extrauniversitarios ${ }^{79}$.

\section{B) Procedimentalmente: se impone la unanimidad (con los Länder) en materia de enseñanza superior}

El artículo 91b 1. LFB no sólo regula el ámbito material de la cooperación entre la Federación y los Länder, sino también la forma a través de la cual ambas instancias pueden interactuar. El nuevo precepto, al igual que sus precedentes, prevé que sean los convenios el cauce a través del cual se concreta dicha cooperación en materia de investigación. Dicha previsión responde a la tradición de cooperación convencional en esta materia. Como se vio, antes de la aprobación de la Ley Fundamental, los Länder suscriebieron el llamado Acuerdo de Königsteiner para abordar la financiación de organismos de investigación ubicados a lo largo y ancho del territorio federal.A finales de los años cincuenta, la Federación entró en dicho convenio y, por ello, la reforma de 1969, optó por llevar a la Ley Fundamental de Bonn una técnica asentada en la praxis cooperativa.

Jarass, B. Pieroth, «Art. 5», Grundgesetz für die Bundesrepublik Deutschland. Kommentar, 14. Aufl., 2016, C.H. Beck, München, pp. 238-242.

76 G. SPEISER, «Der neue Art. 91b GG - zentrale Regelungen und praktische Bedeutung», Recht und Politik, Bd. 51, n. ${ }^{\circ}$ 2, 2015, p. 89.

77 Motivación del Proyecto de reforma constitucional. Bundesrat Drucksache 323/14 p. 4.

78 Enfatizando en la importancia de incluir el fomento de la enseñanza científica, la intervención del Profesor Wolfgang Löwer en la comparecencia ante Comisión de Educación, Investigación y Evaluación del Impacto tecnológico del Bundestag (pp. 24-25): https://www.bundestag.de/blob/338576/14982d0c682e57b7eb360ecf83dcd63b/stellungnahme_loewer-data.pdf (consulta 27.06.2016).

79 J. WolfF, «Der neue Artikel $91 \mathrm{~b}$ GG - Erweiterte Kooperation im Wissenschaftsföderalismus», op. cit., p. 773. 
Los convenios al amparo del artículo 91b 1. LFB deben revestir forma escrita y pueden formalizarse a través de diversas modalidades de suscripción previstas en el Derecho Público alemán ${ }^{80}$. Los convenios son jurídicamente vinculantes y crean derechos y obligaciones para los Gobiernos suscriptores. Esa cooperación convencional lleva a establecer instrumentos orgánicos que den estabilidad a la misma. En este punto, un papel fundamental en la negociación y preparación de estos convenios lo desempeña la Conferencia conjunta entre la Federación y los Länder en materia de Ciencia (GWK) antes vista.

El nuevo artículo 91b 1. LFB tras prever que la Fedeación y los Länder pueden cooperar mediante convenios en el fomento de la investigación en los casos vistos, contempla aspectos procedimentales de esa interacción en su inciso segundo: „Los convenios que afecten en su esencia a los centros de enseñanza superior precisan la aprobación de todos los Länder. Ello no rige para los convenios sobre edificios destinados a la investigación en los centros de enseñanza superior, incluidas las grandes instalaciones de investigación». Como se ha especificado arriba, dentro de centros de enseñanza superior (Hochschulen) no se incluyen sólo Universidades, sino también otros centros (así, Escuelas de Bellas Artes, Música y Pedagogía, Escuelas Superiores Técnicas, o Academias de Ciencias).

El aspecto más polémico de esta previsión es la exigencia de esa unanimidad en los convenios que afecten «en su esencia a centros de enseñanza superior» («die im Schwerpunkt Hocbschulen betreffen»). Ello introduce problemas de interpretación ya que en qué casos se afecta «en su esencia» a dichos centros queda fundamentalmente en manos de la Federación y los Länder en el marco de la negociación de uno de esos convenios. En realidad, la exigencia de unanimidad es una novedad relativa de reforma de 2014, pues se introdujo ya en la reforma federal de 2006, si bien acotada a los convenios para el fomento de proyectos de investigación en los centros de educación superior (anterior art. 91b 1. 2. LFB): por tanto, circunscrita a convenios sobre proyectos temática y temporalmente limitados y sin mención a «en su esencia».

La necesidad de que estos convenios sean aprobados por todos los Länder en los convenios para el fomento conjunto de «la ciencia, la investigación y la enseñanza científica» en los casos en los que se afecte «en su esencia» a los centros de educación superior se ha mantenido en la reforma de 2014. El Profesor Löwer, uno de los influyentes expertos que ha participado en la tramitación parlamentaria de la reforma, ha defendido esa exigencia de unanimidad como «el puerto

80 H. D. Jarass, B. Pieroth, «Art. 91b», Grundgesetz für die Bundesrepublik Deutschland. Kommentar, 14. Aufl., 2016, C.H. Beck, München, p. 1006. Sobre las diversas modalidades de convenios en el Derecho alemán: convenios estatales, que precisan intervención de los Parlamentos (Staatsverträge), convenios adminsitrativos, en el ámbito ejecutivo-adminsitrativo (Verwaltungsabkommen), u otros acuerdos, vid. M.J. GARCía Morales, Convenios de colaboración en los sistemas federales europeos. Estudio comparativo de Alemania, Suiza. Austria y Bélgica, McGraw Hill, Madrid, 1998, pp. 161-163, 169. 
seguro para la igualdad federal» ${ }^{81}$ : esto es, como una garantía de que se adoptaran compromisos y soluciones que favorezcan a todos los Länder. La finalidad de este requisito cualificado es evitar que la Federación lleve a cabo a través de uno de estos convenios un control indirecto de la enseñanza superior (un ámbito que, como se ha visto, corresponde principalmente a los Länder). En aquellos convenios sobre ámbitos científicos donde no se afectan a los centros de enseñanza superior en su esencia no se precisa la aprobación de todos los Länder.

Sin embargo, la unanimidad es un arma de doble filo. Por un lado, ciertamente puede ser una forma de garantizar la igualdad entre todos los Länder, así como una salvaguarda frente a la tendencia centralizadora por la vía financiera de la Federación. Sin embargo, y por otro lado, esta previsión conlleva potencialmente el riesgo de bloqueos, ya que cada Land tiene una posición de fuerza, pues puede ejercitar su veto y, con ello, prolongar el proceso de suscripción o, incluso, impedir la suscripción del convenio. Además, una previsión que, en principio, debe servir para evitar un comportamiento táctico de la Federación consistente en ofrecer dinero selectivamente a algunos Länder, al mismo tiempo, puede ser mal utilizada, de modo que los votos de los Länder se conviertan en moneda de cambio $^{82}$. De este modo, la reforma de 2014 afianza la exigencia de unanimidad en los casos vistos, una disposición que, además, se ha criticado no sólo por el riesgo de bloqueo, sino porque con ello no se favorece la ampliación de la cooperación entre la Federación y los Länder que persigue la reforma de $2014^{83}$.

La unanimidad sólo es necesaria en el caso de los convenios que afectan en su esencia a los centros de enseñanza superior. No es precisa la aprobación por parte de todos los Länder en el caso de convenios entre la Federación y aquellos para edificios e instalaciones destinados a la investigación, al igual que tampoco lo era en la reforma de 2006. Por ello, la cooperación entre la Federación y los Länder para edificios destinados a la docencia o equipamientos universitarios (por ejemplo, residencias o comedores universitarios) sigue siendo ilícita constitucionalmente. Esa formulación aparentemente clara, puede no serlo tanto en la práctica, pues hay edificios que se pueden destinar a investigación y docencia y, en ese caso, habrá que determinar cuál es el elemento predominan$\mathrm{te}^{84}$. Con ello, la nueva reforma tampoco ha zanjado un tema que puede resultar polémico en la práctica.

81 Véase su comparecencia ante la Comisión de Educación, Investigación y Evaluación del Impacto tecnológico del Bundestag (p. 4): https://www.bundestag.de/blob/338576/14982d0c682e57b7eb360ecf$83 \mathrm{dcd} 63 \mathrm{~b} /$ stellungnahme_loewer-data.pdf (consulta 27.06.2016).

82 G. SpeISER, «Das Kooperationsverbot-Status quo und Handlungsoptionen», op. cit., p. 558. Muy interesantes las reflexiones sobre la posición de Veto-Player que abre esa disposición, en M. SECKELMANN, «Artikel 91b», en K.H. Friauf, W. Höfling (Hrsg.), Berliner Kommentar zum Grundgesetz, Band 4, Erich Schmidt Verlag, Berlin, 2016, p. 17.

83 J. WOLFF, «Der neue Artikel 91b GG - Erweiterte Kooperation im Wissenschaftsföderalismus», op. cit., p. 780 .

84 Ibídem, p. 775. 


\section{Y TRAS LA REFORMA, ¿QUÉ?: REFLEXIONES FINALES Y CUESTIONES ABIERTAS}

Por lo menos potencialmente, el principal beneficiario de la reforma de 2014 son los centros de enseñanza superior y, en especial, las Universidades, en cuanto pieza clave de la investigación. En efecto, la reforma de 2014 ha corregido la descompensación que existía ex constitutione entre la financiación conjunta que recibían los centros extrauniversitarios, respecto a los centros de enseñanza superior. La equiparación entre ambos a los efectos de recibir dinero federal ha generado unas expectativas de más financiación que puede permitir mejorar la situación económica de las Universidades alemanas ${ }^{85}$.

La Profesora Johanna Wanka, Ministra federal de Educación e Investigación, y quien presentó el proyecto de reforma dijo, el 10 de octubre de 2014, en el Bundestag: «Nunca como ahora ha existido tanta cooperación entre la Federación y los Länder en el ámbito de la enseñanza superior. [...] No se modifica la Ley Fundamental de Bonn todos los días. Uno piensa: ¿es necesaria esta reforma? Ahí hay que ser claro: nosotros la necesitamos y no se trata de reparar algo que se hizo mal, sino en hacerlo mejor $[\ldots .$.$] se trata de continuar el proceso iniciado» en alu-$ sión a los programas que la Federación y los Länder habían puesto en marcha para potenciar la investigación ${ }^{86}$.

Más allá del discurso político, la reforma de 2014 sí ha supuesto corregir un error, pues suprime lo que mayoritariamente se ha valorado, desde punto de vista técnico, como tal: la prohibición de cooperación entre la Federación y los Länder y los problemas que estaba creando para aprobar y dar continuidad a programas que pretendían impulsar la investigación en Alemania.

Con el nuevo marco constitucional, las expectativas de la reforma parece que se han cumplido y tras su entrada en vigor esa cooperación entre la Federación y los Länder ha podido no sólo tener continuidad, sino que se ha incrementado en este campo y ya con un sólido fundamento normativo.

A las reediciones de programas anteriores (el Pacto por los Centros de Enseñanza Superior, el Pacto por la Calidad de la Enseñanza universitaria o el Pacto para la Investigación y la Innovación), el 16 de junio de 2016, la Canciller federal y los Jefes de Gobierno de la Federación y de los Länder han aprobado conjuntamente un ambicioso paquete global de estrategias para potenciar la investigación con base en el nuevo artículo 91b 1 . LFB, que conlleva una importante inyección de dinero federal: la Estrategia para la Excelencia (Exzellenzstrategie) que permite ya fomentar la cooperación a largo plazo y permanente en centros de enseñanza superior (el gran hándicap antes de la reforma); el Programa para el fomento del

85 A. BorgWardt, «Wer sollte vom neuen Art. 91b GG profitieren?», en A. BorgWardt, Neuer Artikel $91 b$ GG: was ändert sich für die Wissenschaft?, Friedrich Ebert Stiftung, Bonn. 2015, pp. 36-51.

86 Deutscher Bundestag Stenografischer Bericht Planarprotokoll 18/58 pp. 5383, 5384. 
relevo generacional en la carrera investigadora (Programm zur Förderung des wissenschaftlichen Nachwuchses), que pretende dar una salida profesional a jóvenes investigadores; y la Iniciativa «Centros de enseñanza superior innovativos» (Initiative „Innovative Hocbschule»), para potenciar la transferencia de conocimientos de la Universidad a la empresa y a la sociedad ${ }^{87}$.

Evidentemente, las necesidades de financiación en un sector como investigación son muchas y difíciles de cubrir en tiempos de crisis y de contención del gasto. La reforma de 2014 es un paso más en la mejora de la financiación pública de los centros de investigación alemanes, cuya efectividad va a depender de la voluntad política para que los fondos necesarios se conviertan en las dotaciones presupuestarias reales. En cualquier caso, dicha reforma y su debate demuestran que la investigación es una apuesta clave de futuro y, como tal, es tratada como una cuestión de Estado en Alemania. Es una cuestión de Estado porque sobre el Estado (entendido en su conjunto) recae la responsabilidad principal de impulsarla y sostenerla financieramente. $\mathrm{Y}$ eso en un Estado federal significa que incumbe a todos los niveles territoriales: está en la agenda política de la Federación y de los Länder, es debatida, decidida y financiada por ambos niveles.

Desde el punto de vista federal, un punto de vista clave de la reforma de 2014, hay un gran ganador: la Federación que pasa a tener el mayor poder ha tenido en la historia de la Ley Fundamental de Bonn en materia de investigación a través de ese nuevo fundamento constitucional (el art. 91b 1. LFB), pues se han abierto como nunca antes, bajo la República Federal de Alemania el espectro, de actuaciones que se pueden fomentar conjuntamente por la Federación y los Länder en el ámbito de la investigación.

El problema que pretende resolver la reforma de 2014, más allá de peculiaridades autóctonas, ¿es un tema exclusivamente alemán? El problema que plantea esta reforma es un tema clásico en los sistemas federales: el riesgo de invasión competencial del poder central por la vía financiera y, con ello, la subversión del sistema de distribución de competencias operado por la norma constitucional. Por tanto, la historia se repite en el universo federal y, en concreto, se repite en el federalismo alemán donde ya la reforma de 1969 se llevó a cabo para reconducir a la constitucionalidad prácticas en las que la Federación daba dinero a los Länder en ámbitos de sus competencias y bordeaba (o incumplía) la norma constitucional.

Justamente, esa es otra constante del sistema alemán: la voluntad de reconducir a la constitucionalidad prácticas de dudosa legitimidad, pues tanto en 1969, como en 2014, sendas reformas han pretendido dar legitimidad a prácticas cooperativas dudosas para poder inyectar más dinero público (y federal) en ámbitos de los Länder.

87 Más detalles sobre estos programas: https://www.bmbf.de/de/gesamtpaket-fuer-die-hochschulen-beschlossen-3017.html (consulta: 27/06/2016). 
La solución técnica al problema planteado ha sido también una respuesta muy alemana: la opción por regular esa ampliación de la cooperación en una tarea común se inscribe, así, en la tradición alemana, pues las tareas comunes son una figura específica del Derecho Constitucional de aquel país. Esa solución muestra una de las constantes del federalismo alemán: siempre que los Länder necesitan más dinero en un sector específico, la reforma constitucional da base constitucional a la Federación para intervenir en ese ámbito financieramente con los Länder, pero, al optar por una tarea común, ese apoyo financiero se acompaña también de un poder de decisión y de intervención a la Federación en ese ámbito.

Una de las enseñanzas que nos brinda esta reforma de 2014 es la dificultad de prescindir o, por lo menos, reducir la cooperación entre la Federación y los Länder cuando se trata de acometer grandes proyectos en sectores estratégicos.

Justamente, valga recordar que eliminar y disminuir esa cooperación fue uno de los objetivos que pretendió la gran reforma federal de 2006. En el ámbito que nos ocupa, la reducción de las tareas comunes, así como el retorno de competencias a los Länder (en materia de centros de enseñanza superior) no se ha demostrado viable en la práctica. En Alemania, los Länder tienen muchas competencias, pero los recursos más potentes son los federales. La salida a esa paradoja en el sistema alemán ha sido la búsqueda de la cooperación entre la Federación y los Länder y la institucionalización de la misma, al máximo nivel normativo, en la Constitución. De ahí que la nueva reforma de 2014 no sólo no lleva al punto de partida (la reforma de 1969), sino que incrementa los poderes de la Federación en este ámbito como nunca visto en el sistema alemán, pues no sólo puede financiar un ámbito de los Länder, sino que, al hacerlo, gana influencia y poderes de decisión sobre el mismo.

Las lecciones que ofrece la reforma de 2014 no se ciñen ni al sector de la investigación, ni al federalismo, sino también a la propia forma de entender la reforma en Alemania, así como a la diferencia entre la necesidad y la oportunidad de la misma.

La reforma de 2014 muestra que una cosa es tener la idea de reforma y otra muy distinta llevar esa reforma a cabo. Por lo pronto, esta modificación de la Ley Fundamental de Bonn constituye su sexagésima reforma en sus más de sesenta años de vigencia. Es sabido que Alemania es un país donde no existe ni el miedo, ni los problemas que se oponen a la reforma en otras latitudes, entre ellas, la nuestra. Sin embargo, la reforma de la Ley Fundamental de Bonn de 2014 acredita que hasta que no llega la mayoría política necesaria, incluso en un país sin complejos para reformar su Carta Magna, no es posible llevarla a cabo. En este punto, la reforma de 2006 se valoró desde su aprobación como un grave error, pues se trató de un caso claro donde el pacto político primó sobre criterios técnicos que alertaban de las graves consecuencias que tendría dicha regulación en la financiación de la investigación sobre todo universitaria.

No se trataba de un error jurídico cualquiera: la regulación de 2006 estaba en la Constitución. Y enmendar ese error que se había llevado a la Constitución ha costado casi una década resolverlo, pero cuando se ha logrado, se ha hecho — con el 
acuerdo y la voluntad política necesaria - de una forma ciertamente rápida: en sólo seis meses. La reforma de 2014 ha llegado tras un proyecto de reforma fallido y tras unas elecciones federales de 2013 de las que ha surgido la actual gran coalición -la tercera - que gobierna Alemania entre los dos partidos mayoritarios (la democracia cristiana y la socialdemocracia). Con ello, se acredita también que la formación de una gran coalición es una pieza clave para poder acometer la reforma constitucional con garantías de éxito, incluso en un país bregado en reformas constitucionales como es Alemania. Ahora bien, la gran coalición es solo una llave para abrir y aprobar un proceso de reforma, pero, como acredita la experiencia alemana, no garantiza obviamente la calidad, ni el acierto de la regulación adoptada.

No puede concluirse sin señalar que el debate sobre este tema no se encuentra cerrado. Y es que se ha aprobado esta reforma y se pide una nueva reforma constitucional del articulo 91 b que incluya a la educación ${ }^{88}$. La reforma de 2014 no ha abordado una reforma integral del artículo 91b (la tarea común en materia de educación e investigación), sino que sólo ha reformado el párrafo primero relativo a la ampliación de la cooperación entre la Federación y los Länder en el sector de la investigación. Ello ha sido criticado porque aborda una reforma parcial y sólo en el tramo final del circuito educativo (pues afecta sobre todo a las Universidades), pero no del sistema educativo en su integridad con problemas y retos que también se deben encarar ${ }^{89}$.

La famosa novela del escritor alemán Michael Ende La historia interminable es un buen título para ilustrar el debate sobre la supresión o la ampliación de las tareas comunes en la Constitución alemana desde su inserción el siglo pasado o lo que es lo mismo: el debate sobre si debe haber más o menos cooperación entre la Federación y los Länder en la forma constitucional que representan las tareas comunes. El título de este artículo se pregunta ¿qué cambia la reforma de 2014? Esta reforma cambia y mucho las cosas respecto al statu quo anterior. Ha optado por más cooperación en investigación (y por mucha más y en su forma más intensa). El tiempo y la oportunidad política dirán si la reforma de 2014 es el último capítulo de la tarea común del artículo 91b LFB (y en general las tareas comunes) en el federalismo alemán o, por el contrario, la historia continuará.

TITLE: Research and Federalism: the Reform in 2004 of the German Constitution. What has Changed?

ABstRACT: Effective as of January 1 2015, the latest reform of the Basic Law for the Federal Republic of Germany has re-drafted Paragraph 1 of Article 91b of the Basic Law, which regulates the rela-

88 Así, la moción de Die Linke, de 4 de diciembre de 2015: Antrag der Fraktion Die Linke Deutscher Bundestag Drucksache 18/6875.

89 El propio Bundesrat al aprobar la reforma de 2014 ya había señalado la necesidad en el futuro de acometer los retos en el conjunto de sector educativo «con nuevas formas de cooperación y un mayor compromiso de la Federación»: Deutscher Bundestag Drucksache 18/2710 Stellungnahme des Bundesrates p. 8. 
tionships between the Federation and the Länder regarding the promotion of scientific research. The new provision has sought to resolve the serious consequences created by the wording given to same by the great federal reform of 2006. The 2014 reform thus constitutes the response to the open debate in the last decade in Germany on the need to remove a regulation which prevented the Federation from participating financially alongside the Länder in research institutions of higher education establishments and of the Universities in particular. This Article analyses the scope of this new regulation, which has raised significant expectations for improved funding for these establishments, but also questions that will need to be specified in practice.

Resumen: Con efectos desde el 1 de enero de 2015, la última reforma de la Ley Fundamental de Bonn ha dado una nueva redacción al párrafo 1 del artículo 916 LFB donde se regulan las relaciones entre la Federación y los Länder en materia de fomento de la investigación científica. El nuevo precepto ha pretendido resolver las graves consecuencias que habia generado la redacción que le dio al mismo la gran reforma federal de 2006. Con ello, la reforma de 2014 constituye la respuesta al debate abierto en la última década en Alemania sobre la necesidad de suprimir una regulación que impedía a la Federación participar financieramente junto a los Länder en instituciones de investigación de los centros de enseñanza superior y, en particular, de las Universidades. En este artículo, se analiza el alcance de esta nueva regulación que ha abierto notables expectativas sobre todo respecto a la mejora de la financiación de dichos centros, pero también interrogantes que deberán concretarse en la práctica.

KEY wORDS: Research, science, federalism, Basic Law for the Federal Republic of Germany, constitutional reform.

Palabras Clave: Investigación, ciencia, federalismo, Ley Fundamental de Bonn, reforma constitucional.

FECHA DE RECEPCIÓN: 25.06.2016

FECHA DE ACEPTACIÓN: 27.07.2016 